\title{
Reduction of Power Imbalances Using Battery Energy Storage System in a Bulk Power System with Extremely Large Photovoltaics Interactions
}

\author{
Rajitha Udawalpola ${ }^{1,2,3} \mathbb{D}^{D}$, Taisuke Masuta ${ }^{3, *}$, , Taisei Yoshioka ${ }^{3}$, Kohei Takahashi ${ }^{3}$ and Hideaki Ohtake ${ }^{4}(\mathbb{D}$ \\ 1 Department of Electrical and Information Engineering, Faculty of Engineering, University of Ruhuna, \\ Galle 80000, Sri Lanka; rajitha@eie.ruh.ac.lk \\ 2 Department of Natural Resources and the Environment, University of Connecticut, Storrs, CT 06269, USA \\ 3 Department of Electrical and Electronic Engineering, Faculty of Science and Technology, Meijo University, \\ Nagoya 468-8502, Japan; 160442151@ccalumni.meijo-u.ac.jp (T.Y.); 150442067@ccalumni.meijo-u.ac.jp (K.T.) \\ 4 Fukushima Renewable Energy Institute, National Institute of Advanced Industrial Science and Technology \\ (AIST), Fukushima 963-0298, Japan; hideaki-ootake@aist.go.jp \\ * Correspondence: masuta@meijo-u.ac.jp; Tel.: +81-52-838-2631
}

check for updates

Citation: Udawalpola, R.; Masuta, T.; Yoshioka, T.; Takahashi, K.; Ohtake, H. Reduction of Power Imbalances Using Battery Energy Storage System in a Bulk Power System with Extremely Large Photovoltaics Interactions. Energies 2021, 14, 522. https://doi.org/10.3390/en14030522

Academic Editor: Wilfried van Sark Received: 21 December 2020 Accepted: 14 January 2021 Published: 20 January 2021

Publisher's Note: MDPI stays neutral with regard to jurisdictional clai$\mathrm{ms}$ in published maps and institutional affiliations.

Copyright: $\odot 2021$ by the authors. Licensee MDPI, Basel, Switzerland. This article is an open access article distributed under the terms and conditions of the Creative Commons Attribution (CC BY) license (https:// creativecommons.org/licenses/by/ $4.0 /)$.

\begin{abstract}
Power imbalances such as power shortfalls and photovoltaic (PV) curtailments have become a major problem in conventional power systems due to the introduction of renewable energy sources. There can be large power shortfalls and PV curtailments because of PV forecasting errors. These imbalances might increase when installed PV capacity increases. This study proposes a new scheduling method to reduce power shortfalls and PV curtailments in a PV integrated large power system with a battery energy storage system (BESS). The model of the Kanto area, which is about $30 \%$ of Japan's power usage with 60 GW grid capacity, is used in simulations. The effect of large PV power integration of $50 \mathrm{GW}$ and $100 \mathrm{GW}$ together with large BESS capacity of $100 \mathrm{GWh}$ and $200 \mathrm{GWh}$ has been studied. Mixed integer linear programming technique is used to calculate generator unit commitment and BESS charging and discharging schedules. The simulation results are shown for two months with high and low solar irradiance, which include days with large PV over forecast and under forecast errors. The results reveal that the proposed method eliminates power shortfalls by $100 \%$ with the BESS and reduce the PV curtailments by $69.5 \%$ and $95.2 \%$ for the months with high and low solar irradiance, respectively, when 200 GWh BESS and 100 GW PV power generation are installed.
\end{abstract}

Keywords: batter energy storage systems; forecast errors; mixed integer linear programming; photovoltaic forecasting; unit commitment

\section{Introduction}

In recent years, the introduction of renewable energy has been significantly promoted all over the world. In Japan, the installed capacity of photovoltaic (PV) power generation has been increasing. Although the accumulated installed PV capacity in Japan was only 5.6 GW in June 2012, it reached 50.2 GW in March 2019 [1,2]. That is approximately $25 \%$ of the total grid capacity of Japan. The Japanese government has set $64 \mathrm{GW}$ as the installation target of PV power generation in 2030 [3]. However, $70 \%$ of the target has already been installed and some estimates indicate that it will be between $100 \mathrm{GW}$ and 300 GW in 2030 [4-6]. Thermal power generators have an important role in supply-demand maintenance in bulk power systems. Large-scale thermal power generator activations should be scheduled in advance because it takes a long time to startup or shutdown. The generator schedule for the current day, which is called unit commitment (UC) schedule, is generally determined in the previous day. The activation of thermal power generators follows the UC schedule in the current day operation. The operating generators regulate the outputs for supply-demand balance maintenance. In power systems with large PV power 
generation, the UC schedule is determined using the forecasted PV power outputs and the thermal power outputs. The activations of generators cannot be changed at once. Therefore the forecast accuracy improvement is important because supply-demand imbalances may occur due to forecast errors [7]. Supply-demand imbalance is divided into power shortfall and surplus. Although power shortfall can be completely avoided with high forecast accuracy, power surplus may occur even if the forecast is completely accurate [8]. For example, if $15 \mathrm{GW}$ of the PV power generation is installed in the power systems with $10 \mathrm{GW}$ of the maximum load, the generated PV power cannot be consumed by the load and must be curtailed through PV power curtailment. Therefore, a hybrid solution with PV power systems and energy storage devices such as battery energy storage systems (BESSs) are necessary to efficiently use the surplus.

Hybrid solutions with different energy systems have been proposed to integrate renewable energy generation into conventional power systems. Margeta and Glasnovic [9] have suggested a photovoltaic-hydro hybrid system for sustainable energy production. Francois et al. [10] have studied combined solar and run-of-river power in northern Italy. Ghadikolaei et al. [11] have studied scheduling of hydro-wind hybrid system considering uncertainties. Angarita et al. [12] have proposed a joint hydro-wind scheduling method using stochastic optimization method. Shabani and Mahmoudimehr [13] have compared PV pump storage hydroelectric system with the common PV-battery system. Campana et al. [14] have optimized PV water pumping systems to design a cost effective system. Purvins et al. [15] have studied several options for managing an electricity system and their effectiveness on large-scale wind power integration.

If the energy storage devices are incorporated to the power systems, they would make scheduling methods for power system operation more complicated. Yang et al. [16] have done a comprehensive study on UC with renewable generation and plug-in electric vehicles (PEVs). They have integrated a stochastic wind power model and solar energy model in day-ahead UC. They have shown that using PEVs for charging and discharging can reduce the total operational cost than using only for charging. Luburić and Pandžić [17] have investigated the Flexible AC Transmission System (FACTS) devices and Energy Storage devices in IEEE RTS96 system using mixed integer linear programming (MILP). They have shown that energy storage devices are more effective in reducing the operational cost that FACTS devices. Fu et al. [18] have used MILP to investigate the performance of renewable energy sources with pumped hydroelectric energy storage (PHES). They have shown PHES can be used to decrease the output of thermal units and to balance wind power fluctuation according to the load demand. El Azab et al. [19] have investigated different combinations of renewable energy sources and plug-in electric vehicles to reduce combined economic emission dispatch. They have used a meta-heuristic water cycle optimization algorithm to get optimal scheduling. They have compared results with dynamic programming and genetic algorithm to validate the results.

Due to the unreliability of renewable energy sources, conventional optimization methods cannot be used effectively to find the optimal solution. Stochastic or meta-heuristic optimization methods have been popular in finding optimal solutions involving renewable energy sources because of unreliability. Zheng et al. [20] have comprehensively reviewed different stochastic optimization algorithms in UC. Saleh et al. [21] have comprehensively reviewed the recent approaches of UC in the presence of renewable energy sources. Luo et al. [22] have suggested a new modified bat algorithm to find the optimal scheduling for a microgrid system including a photovoltaic, wind energy, fuel cell and battery energy storage system. The proposed algorithm leads to a faster computation time compared to other evolutionary optimization methods. Wang et al. [23] have analyzed the relationship between operational cost and wind curtailment using multi-objective UC. They have modeled the objective function and constraints as a nonlinear function and found the optimal solution using particle swarm optimization.

To handle the unreliability of PV power generation, our research group has focused on the application of the PV power generation forecast and the contribution of BESS 
to the supply-demand schedule and operation for power systems with large PV power generation [7,8,24]. In the previous study, Kobayashi et al. [24] proposed a coordinated operation method for thermal power generators and a large BESS in a bulk power system. They showed that the supply-demand imbalance was reduced by updating the generator UC and BESS schedules based on the PV power generation forecasts released every $6 \mathrm{~h}$. However, the reduction effect became worse with larger values of the installed PV capacity due to the forecast errors. More frequent updates for the schedules based on more frequent releases of PV forecasts would improve the effectiveness of the reduction of power imbalances.

Various studies have been done on supply-demand schedule update. An energy management system for a microgrid which consists of wind and PV power generations, diesel generators and BESS is proposed by Palma-Behnke et al. [25] where the schedule including the UC was updated every hour. The grid capacity was only $28 \mathrm{~kW}$ and the detailed constraints for diesel generators had not been considered in [25]. The generator UC and BESS charge/discharge for every $0.5 \mathrm{~h}$ for $6 \mathrm{GW}$ grid capacity of the IEEE 118-bus system has been calculated by Warrington et al. [26]. The up/down time constraints were not considered, and a simple forecast model based on the normal distribution function was employed in [26]. Vagropoulos et al. [27] sequentially scheduled and evaluated the supply-demand operation of a $550 \mathrm{MW}$ power grid for one year. However, the sudden supply-demand imbalances could not be handled because the schedule was updated only once a day. Saint-Pierre et al. [28] evaluated the impact of the update frequency and the schedule period on the supply-demand operation of $11 \mathrm{kV}$ distribution networks where the UC schedule of large generators in bulk power systems were not focused.

In this study, a new scheduling method is proposed for determining the actual operation of the generators and the BESS while updating the generator UC and BESS schedules. The proposed method, which uses MILP technique, performs a rapid update with an interval of $0.5 \mathrm{~h}$ for the schedules based on the actual PV power outputs at the current time and the most recent forecasted PV power outputs. The actual PV power output at the current time observed every $0.5 \mathrm{~h}$, and the forecast dataset (period: $38.5 \mathrm{~h}$ ahead, unit time: $0.5 \mathrm{~h}$ ) released every 3 hours are employed. The detailed operation constraints of thermal generators and BESS such as ramp rate, up/down time and the state of charge (SoC) are considered, which were not taken into account in the previous study [24]. The effectiveness of the proposed method is evaluated by numerical simulations conducted on a bulk power system model with over 100 thermal generators. The impacts of the installed PV and BESS capacities are also analyzed. The network constraint of the power system and BESS sizing and placement is not considered in this study. The installation or maintenance cost of energy generators or BESS is also not considered. Such costs are important for making investment planning or grid planning. Kryzia et al. [29] have examined the operational flexibility of energy investment using combined cycle turbines but our study mainly focuses on the system operation part.

There are few research works found in the literature which engaged on the schedule update for bulk power systems considering the detailed constraints of a large number of thermal generators and the meteorological forecast model. Most of the research literature focuses on the optimal scheduling of generators and energy sources. In this study, the power imbalances that occur at the real-time are studied. These studies are very important to the utilities which have the responsibility to maintain the supply-demand balance in the real-time operation as well as to make the daily supply-demand schedule with sufficient upward/downward reserve capacities.

\section{Operation and Schedule Update Method for Generators and a Large BESS}

\subsection{Time Chart of the Schedule Update}

In this study, a large number of thermal power generators and a large BESS are used for supply-demand maintenance based on the total actual and forecasted PV power outputs installed in the whole power system. In general, it takes a long time to startup or shutdown 
large thermal power generators. We assume that the activations of the thermal power generators cannot be changed from the current time to $6 \mathrm{~h}$ ahead. We examine two case studies that determine and update the BESS and generator UC schedules. We only consider the forecast errors of PV power outputs assuming that the load demand can be accurately forecasted. In this study, $0.5 \mathrm{~h}$ time resolution is used for the UC and BESS schedules.

\subsubsection{Case 1 (Base Case)}

Case 1 is considered as the base case. In Case 1, the generator UC schedules from 00:30 to 24:00 local time (LT, LT $=$ UTC $+9 \mathrm{~h}$ ) of the day $n+1$ and BESS schedules from 19:00 LT of the day $n$ to 24:00 LT of the day $n+1$ are determined based on the forecasted PV power outputs released at 18:30 LT of the previous day. The schedules are determined only once and not updated until 18:30 LT of the day $n$. After the release of the 18:30 LT forecast of the day $n+1$, the UC and BESS schedules are updated in the same way for day $n+2$.

In the current day operation, the generators startup and stop follow the day-ahead UC schedule whereas the BESS charge and discharge follow the day-ahead charging and discharging schedule. The operating generators regulate the outputs to maintain the electricity supply-demand balance. As a result that the activations of the generators cannot be changed from the day-ahead UC schedule, the load shedding (power shortfall) or the PV power curtailment (power surplus) will be done to maintain the supply-demand balance when the total PV power output is out of the range of the total reserve capacity. Figure 1 shows the time chart of the schedule and operation in Case 1. The vertical axis represents the current time $\left(T^{c u}\right)$ and the horizontal axis represents the time interval of the BESS and UC schedules and forecast period.

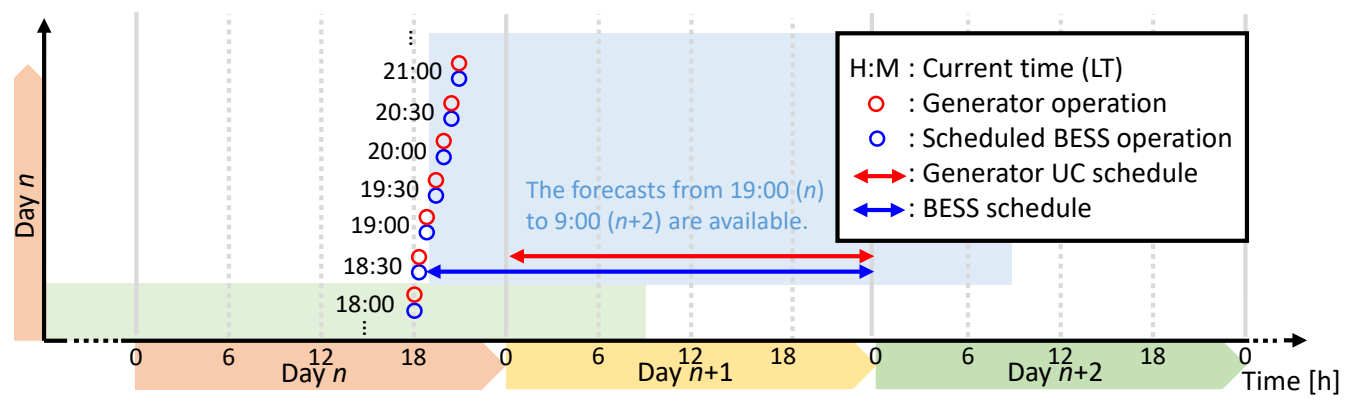

Figure 1. Case 1 time chart; unit commitment (UC) and battery energy storage system (BESS) schedule is calculated once a day from 19:00 LT of day $n$ to 24:00 of day $n+1$ using forecast at 18:30 LT on day $n$.

\subsubsection{Case 2 (Proposed Case)}

Case 2 is the proposed scheduling method in this study. Figure 2 shows the time chart of the schedule and operation in Case 2. The operating points of the generators and the actual operation of the BESS are calculated and those schedules are updated at the current wall time $\left(T^{c u}\right)$. The operating point calculation and the schedule update are both repeated by the unit time of $0.5 \mathrm{~h}$. The datasets of the PV power generation forecast from $0.5 \mathrm{~h}$ ahead to $38.5 \mathrm{~h}$ ahead (unit time: $0.5 \mathrm{~h}$ ) are released every $3 \mathrm{~h}$. As shown in Figure 2, five datasets released from 9:30 LT of Day $n$ to 21:30 LT of Day $n$ can be used for the schedule from 0:30 LT to 24:00 LT of Day $n+1$.

On Day $n$, the BESS charge/discharge power and the thermal power generator outputs are set at time $T^{c u}$. When $T^{c u}$ is between 0:30-9:00 LT, the charging and discharging schedule from $T^{c u}+0.5 \mathrm{~h}$ to 24:00 LT of the same day (day $n$ ) and the generator UC schedule from $T^{c u}+6 \mathrm{~h}$ to 24:00 LT of the same day is calculated. When $T^{c u}$ is between 9:30 and 24:00 LT the charging and discharging schedule from $T^{c u}+0.5 \mathrm{~h}$ to 24:00 LT of the following day (day $n+1$ ) and the generator UC schedule from $T^{c u}+6 \mathrm{~h}$ to 24:00 LT of the following day is calculated. 
For example, when $T^{c u}$ is 11:30 LT of Day $n$, the BESS power and the generator outputs at 11:30 LT are determined at the same time as the BESS schedule from 12:00 LT of Day $n$ to 24:00 of Day $n+1$ and generator UC from 17:30 LT of Day $n$ to 24:00 of Day $n+1$ are updated based on the actual PV power output at 11:30 LT and the forecast dataset released at 9:30 LT of Day $n$ for half-hourly values from 10:00 LT of Day $n$ to 24:00 LT of Day $n+1$.

\subsection{Problem Formulation}

\subsubsection{Optimization Problem}

We find the unit commitment of thermal generators $\left(u_{i, t}\right)$, and BESS charging schedule $\left(p_{t}^{b c}\right)$ and discharging schedule $\left(p_{t}^{d c}\right)$ in an optimization horizon $(T)$ by minimizing the function

$$
f=\sum_{i=1}^{N} \sum_{t=t_{c}}^{T}\left\{u_{i, t} \mathrm{FC}_{i}\left(p_{i, t}\right)+s_{i, t} \mathrm{SC}_{i}\right\}+\sum_{t=t_{c}}^{T}\left\{\operatorname{curt}_{t}^{l d} \mathrm{LC}_{t}+\operatorname{curt}_{t}^{p v} \mathrm{PC}_{t}\right\}+x_{s o c} \mathrm{C}_{s o c},
$$

where the fuel cost function is

$$
\mathrm{FC}_{i}\left(p_{i, t}\right)=a_{i}+b_{i} p_{i, t}+c_{i} p_{i, t}^{2} .
$$

subjected to linear constraints (3)-(23). Here we use generator status $\left(u_{i, t}\right)$ start up cost $\left(s_{i, t}\right)$, PV curtailment (curt $\left.{ }_{t}^{p v}\right)$, load curtailment $\left(\right.$ curt $\left._{t}^{l d}\right)$ and SoC difference $\left(x_{s o c}\right)$ as decision variables in the objective function.

Supply-demand constraint at time $t$ is given as

$$
\sum_{i=1}^{N} u_{i, t} p_{i, t}+P_{t}^{n u}+P_{t}^{h}+P_{t}^{p v}-\operatorname{curt}_{t}^{p v}+p_{t}^{b d}=P_{t}^{l d}-\operatorname{curt}_{t}^{l d}+p_{t}^{b c}, \quad \forall t_{c} \leq t \leq T .
$$

The power supplied at time $t$ by thermal generator $i$ is $p_{i, t}$, PV generation is $P_{t}^{p v}$, nuclear power plants is $P_{t}^{n u}$ and hydro power plants is $P_{t}^{h} . P_{t}^{l d}$ is the load at time $t$. Here, extra photovoltaic power and load is curtailed at an extremely higher penalty value in the objective function.

Load frequency control (LFC) and thermal operation constraints are represented as

$$
\begin{aligned}
& u_{i, t}\left(P_{i, t}^{\min }+C_{i}^{l f c}\right) \leq u_{i, t} p_{i, t} \leq u_{i, t}\left(P_{i}^{\max }-C_{i}^{l f c}\right), \\
& \sum_{i=1}^{N} u_{i, t} C_{i}^{l f c}+C^{h} \geq R^{d}\left(P_{t}^{l d}-\operatorname{curr}_{t}^{l d}\right)+R^{p v}\left(p_{t}^{p v}-\operatorname{curr}_{t}^{p v}-p_{t}^{b c}\right),
\end{aligned}
$$

where

$$
C_{i}^{l f c}=0.05 P_{i}^{\max } \text { and } t_{c} \leq t \leq T .
$$

Here, $P_{i, t}^{\min }$ and $P_{i}^{\max }$ are minimum and maximum rated output power at time $t$ of generator $i$. The operating generators can generate power by removing $\operatorname{LFC}\left(C_{i}^{l f c}\right)$. 


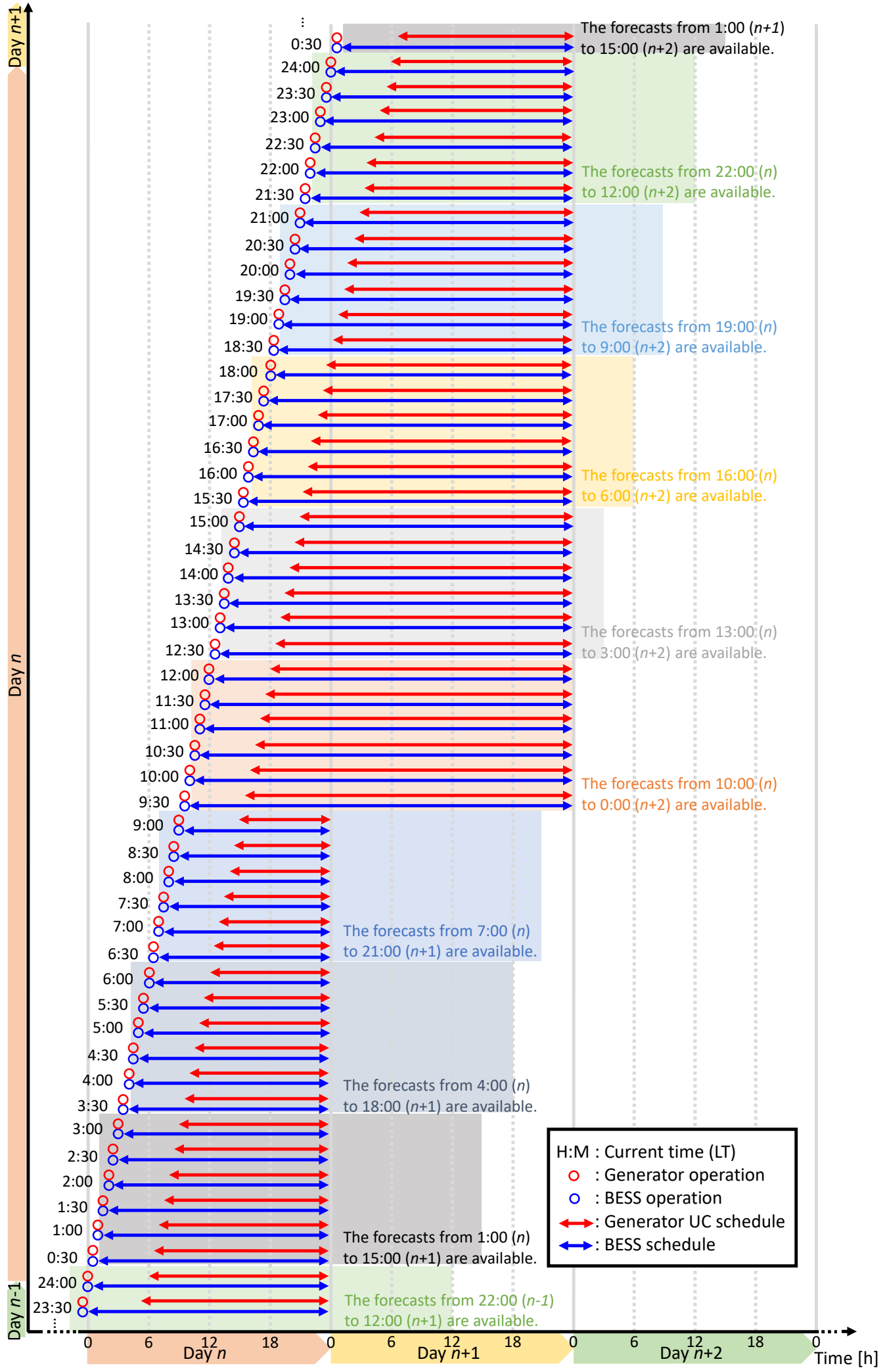

Figure 2. Case 2 schedule for UC and BESS operations. Vertical axis represent the current time and horizontal axis represents the time interval of BESS and UC schedules.

The reserve capacity constraint can be formulated as

$\sum_{i=1}^{N} u_{i, t} P_{i}^{\max }+P^{n u}+P^{h}+P_{t}^{p v}-\operatorname{curr}_{t}^{p v}+p_{t}^{b d} \geq\left(1+R^{o}\right) P_{t}^{l d}+p_{t}^{b c}, \quad \forall t_{c}+11 \leq t \leq T$. 
Here, $R^{o}$ is the ratio of upward reserve capacity.

BESS charging and discharging is represented as follows.

$$
\begin{aligned}
& 0 \leq p_{t}^{b c} \leq x_{t} P_{i n v}^{b c}, \\
& 0 \leq p_{t}^{b d} \leq y_{t} P_{i n v}^{b d}, \\
& 0 \leq x_{t}+y_{t}<1 .
\end{aligned}
$$

Here binary variables $x_{t}$ and $y_{t}$ are used to mutually exclude charging and discharging of the BESS and $P_{i n v}^{b c}$ and $P_{i n v}^{b d}$ are charging and discharging inverter power of BESS, respectively.

The charging and discharging of the BESS can be formulated as

$$
\begin{aligned}
c_{t}^{B} & =c_{t-1}^{B}+\eta p_{t}^{b c} \Delta T+p_{t}^{b d} \Delta T, \quad \forall t>t_{c}, \\
0 & \leq c_{t}^{B} \leq C_{\max }^{B},
\end{aligned}
$$

where $c_{t}^{B}$ is the SoC of BESS at time $t, \eta$ is the battery efficiency and $C_{\max }^{B}$ is the maximum battery SoC capacity. At the start of the simulation, we set the BESS SoC to $50 \%$ of the maximum BESS SoC capacity.

We apply constraints to the SoC condition of the battery. We do not use rigid constraints to allow flexibility in the optimization problem. We do this by minimizing the absolute value of the $c_{t}^{B}-0.5 C_{\max }^{B}$ where $t=t_{\mathrm{mn}}$. The SoC condition at midnight of each day is forced to be closed to $50 \%$ of the total using a penalty in the objective function and by using the constraints,

$$
\begin{aligned}
& c_{t}^{B}-0.5 C_{\max }^{B} \leq x_{s o c}, \\
& 0.5 C_{\max }^{B}-c_{t}^{B} \leq x_{s o c} .
\end{aligned}
$$

for all $t$ where $t=t_{\mathrm{mn}}$.

Ramp up and down constraints are given as

$$
\begin{aligned}
& p_{i, t}-p_{i, t-1} \leq R_{i}^{u p} u_{i, t}+p_{i}^{\text {min }} s_{i, t} \\
& p_{i, t-1}-p_{i, t} \leq R_{i}^{\text {down }} u_{i, t}+p_{i}^{\text {max }} d_{i, t},
\end{aligned}
$$

where $R_{i}^{u p} u_{i, t}$ and $R_{i}^{\text {down }} u_{i, t}$ are ramp-up rate and ramp-down rate of generator $i$ at time $t$, respectively. Here, we assume that the startup power rate is $p_{i}^{\min }+R_{i}^{u p}$ for generator $i$ and the generator can be taken out from the system at any operating point below $p^{\max }$.

Minimum down time $\left(D T_{i}\right)$ of the generator $i$ at time $t^{\prime}$ is given by the constraint

$$
\sum_{t=t^{\prime}}^{t^{\prime}+D T_{i}}\left(1-u_{i, t}\right) \geq D T_{i}\left(u_{i, t^{\prime}-1}-u_{i, t^{\prime}}\right) \quad \forall t_{c} \leq t^{\prime} \leq T
$$

Minimum up time $\left(U T_{i}\right)$ of the generator $i$ at time $t^{\prime}$ is given by the constraint

$$
\sum_{t=t^{\prime}}^{t^{\prime}+U T_{i}} u_{i, t} \geq U T_{i}\left(u_{i, t^{\prime}}-u_{i, t^{\prime}-1}\right) \quad \forall t_{c} \leq t^{\prime} \leq T
$$

In the MILP formulation, we use piece-wise linear approximation of the fuel cost function in Equation (2). The piece-wise linear approximation is achieved using following formulation

$$
p_{i, t}=u_{i, t} P_{i}^{m i n}+\sum_{k=1}^{L} v_{i, t}^{k} \lambda_{i}^{k}
$$

where 


$$
\begin{aligned}
h_{i} w_{i, t}^{k} & <=v_{i, t}^{k} \\
v_{i, t}^{k} & <=h_{i} u_{i, t}, \quad \text { for } k=1
\end{aligned}
$$

and

$$
\begin{aligned}
h_{i} w_{i, t}^{k} & <=v_{i, t}^{k} \\
v_{i, t}^{k} & <=h_{i} w_{i, t}^{k-1} \quad \forall k>1 .
\end{aligned}
$$

For Case 2, we update the thermal and BESS schedule at each cycle $\gamma$. We assume that it takes $6 \mathrm{~h}$ from the current time to start-up or stop each thermal power generator. The time resolution in the optimization horizon is $0.5 \mathrm{~h}$. Therefore, the activation of the generators from $t_{c}$ to $t_{c}+11$ is done according to the previous schedule as

$$
u_{i, t}^{(\gamma+1)}=u_{i, t+1}^{\gamma} \quad \text { for } t_{c} \leq t \leq\left(t_{c}+11\right) .
$$

The time $t$ in current cycle $\gamma$ corresponds to the $t+1$ in cycle $\gamma-1$. The SoC of the BESS is updated from the previous schedule cycle at $t=t_{c}$.

$$
c_{t_{c}}^{B_{\gamma+1}}=c_{\mathrm{t}_{\mathrm{c}}+1}^{B_{\gamma}} \text { for } \gamma>0 .
$$

\subsubsection{Economic Dispatch}

We find economic dispatch for current time $t_{c}$ by minimizing the function

$$
f_{t_{c}}=\sum_{i=1}^{N} U_{i, t_{c}} \cdot \mathrm{FC}_{i}\left(p_{i, t_{c}}\right)+c u r t_{t c}^{l d} \mathrm{LC}_{t_{c}}+c u r t_{t c}^{p v} \mathrm{PC}_{t_{c}}
$$

where

$$
\mathrm{FC}_{i}\left(p_{i, t_{c}}\right)=a_{i}+b_{i} p_{i, t_{c}}+c_{i} p_{i, t_{c}}^{2} .
$$

subjected to following constraints. Here, $U_{i, t_{c}}$ is the day ahead generator schedule calculated by the day ahead unit commitment.

Supply-demand constraint at time $t$ is given as

$$
\sum_{i=1}^{N} U_{i, t_{c}} p_{i, t_{c}}+P_{t_{c}}^{n u}+P_{t_{c}}^{h}+P_{t_{c}}^{p v}-c u r t_{t c}^{p v}=P_{t c}^{d}-c u r t_{t c}^{l d}-P_{t_{c}}^{b d}+P_{t_{c}}^{b c} .
$$

Here, power shortfall and power surplus can occur with extremely higher cost in the objective function in Equation (25). $P_{t_{c}}^{b c}$ and $P_{t_{c}}^{b d}$ are the BESS charging and discharging values calculated by the BESS schedule, respectively.

LFC and thermal operation constraints are represented as

$$
\begin{aligned}
& U_{i, t_{c}}\left(P_{i}^{\min }+C_{i}^{l f c_{c}}\right) \leq U_{i, t_{c}} p_{i, t_{c}} \leq U_{i, t_{c}}\left(P_{i}^{\max }-C_{i}^{l f c_{c}}\right), \\
& \sum_{i=1}^{N} U_{i, t_{c}} C_{i}^{l f_{c}}+C^{h} \geq R^{d} p_{t_{c}}^{d}+R^{p v} P_{t_{c}}^{p v} .
\end{aligned}
$$

Ramp up and down constraints can be formulated as

$$
\begin{aligned}
& p_{i, t_{c}}-p_{i, t_{c}-1} \leq R_{i}^{u p} u_{i, t_{c}}+\left(p_{i}^{\max }-R_{i}^{u p}\right) s_{i, t_{c}} \\
& p_{i, t_{c}-1}-p_{i, t_{c}} \leq R_{i}^{\text {dowo }} u_{i, t_{c}}+\left(p_{i}^{\max }-R_{i}^{\text {down }}\right) d_{i, t_{c}} .
\end{aligned}
$$


The optimization problem is solved using MILP method. Therefore the quadratic fuel cost function is expressed as a piece-wise linear function using the following constraints.

$$
p_{i, t_{c}}=U_{i, t_{c}} P_{i}^{\text {min }}+\sum_{k=1}^{L} v_{i, t_{c}}^{k} \lambda_{i}^{k}
$$

where

$$
\begin{aligned}
h_{i} w_{i, t_{c}}^{k}< & =v_{i, t_{c^{\prime}}}^{k} \\
v_{i, t_{c}}^{k}< & =h_{i} u_{i, t_{c^{\prime}}} \quad \text { for } k=1
\end{aligned}
$$

and

$$
\begin{aligned}
h_{i} w_{i, t_{c}}^{k}< & =v_{i, t_{c}}^{k} \\
v_{i, t_{c}}^{k} & <=h_{i} w_{i, t_{c}}^{k-1} \quad \forall k>1 .
\end{aligned}
$$

\section{Simulation}

Numerical simulations are conducted on a power system model of the Kanto area of Japan, which is the largest power system in Japan with approximately $60 \mathrm{GW}$ of the grid capacity. The model of the Kanto area is employed to verify the effectiveness of the proposed method in large bulk power systems. In the simulations, we assume an extremely large integration of PV power generation and BESS in the future [6]. The simulation period is two months (April and January) with high and low solar irradiance. Both months have days with under forecast and over forecast errors. The time step is $0.5 \mathrm{~h}$ because that of UC schedules generally range from $15 \mathrm{~min}$ to $1 \mathrm{~h}$. We assume the two cases for the simulations as noted in Section 2.1. The optimization problem was solved using Gurobi Optimizer 9.1 [30] with MILP solver.

\subsection{Simulation Conditions}

\subsubsection{Power and Control Resources}

Table 1 shows the installed capacities of the conventional power plants in the Kanto area of Japan, which was assumed in the previous study [24]. The nuclear power plant output is constant at $100 \%$ of the installed capacity. The hydro-power plant output is constant at $95 \%$ of the installed capacity and the remaining $5 \%$ is used for the LFC operation. Table 2 shows the specifications of the thermal power generators, which are based on [31,32]. The operational constraints of generators such as ramp-up/down rates and up/down times are mainly based on technical report, recommended a simulation model for automatic generation control [32], by the Institute of Electrical Engineers of Japan (IEEJ). Two values of installed PV capacity, 50 and $100 \mathrm{GW}$, are used in the simulations. The $100 \mathrm{GW}$ of the installed PV capacity in the Kanto area corresponds to $300 \mathrm{GW}$ of all Japan, which is the extreme target in [6]. The actual installed PV capacity was approximately $14 \mathrm{GW}$ in this area in March 2020 [33]. An extremely large PV installation that can be installed out in the future is used for the simulations. The installed BESS capacity, which is currently almost zero in this area, is also considered as a parameter, $0 \mathrm{GW} / 0 \mathrm{GWh}, 50 \mathrm{GW} / 100 \mathrm{GWh}$ and 100 GW/ 200 GWh (inverter capacity of the BESS in GW/battery capacity of the BESS in GWh). 
Table 1. Installed nuclear, hydro and thermal capacity in MW in the Kanto Area of Japan [24].

\begin{tabular}{cc}
\hline & Installed Capacity (MW) \\
\hline Nuclear & 6000 \\
Hydro & 1200 \\
Thermal & $60,850(168$ machines $)$ \\
\hline
\end{tabular}

Table 2. Parameters of thermal generators [31,32].

\begin{tabular}{|c|c|c|c|c|c|c|c|c|c|c|c|c|}
\hline & \multirow{2}{*}{$\begin{array}{l}\text { Rated } \\
\text { Output } \\
\text { (MW) }\end{array}$} & \multirow{2}{*}{$\begin{array}{r}\text { Lower } \\
\text { Limit } \\
\text { (MW) }\end{array}$} & \multicolumn{3}{|c|}{ Coefficient of Fuel Cost Function } & \multirow{2}{*}{$\begin{array}{l}\text { Start-up } \\
\text { Cost } \\
\text { (JPY) }\end{array}$} & \multirow{2}{*}{$\begin{array}{l}\text { Ramp } \\
\text {-Up } \\
\text { Rate } \\
\text { (\%MW } \\
\text { /min.) }\end{array}$} & \multirow{2}{*}{$\begin{array}{l}\text { Ramp } \\
\text {-Down } \\
\text { Rate } \\
\text { (\%MW } \\
\text { /min.) }\end{array}$} & \multirow{2}{*}{$\begin{array}{c}\text { Up } \\
\text { Time } \\
\text { (h) }\end{array}$} & \multirow{2}{*}{$\begin{array}{l}\text { Down } \\
\text { Time } \\
\text { (h) }\end{array}$} & \multirow{2}{*}{$\begin{array}{l}\text { Num- } \\
\text { ber } \\
\text { of } \\
\text { Gene- } \\
\text { Rators }\end{array}$} & \multirow{2}{*}{$\begin{array}{c}\text { Total } \\
\text { Capacity } \\
\text { (MW) }\end{array}$} \\
\hline & & & $\begin{array}{c}a_{i} \\
\text { (JPY } \\
/ \mathrm{MWh})\end{array}$ & $\begin{array}{c}b_{i} \\
(\mathrm{JPY} \\
/ \mathrm{MWh})\end{array}$ & $\begin{array}{c}c_{i} \\
(\mathrm{JPY} \\
\left./ \mathrm{MW}^{2} \mathrm{~h}\right)\end{array}$ & & & & & & & \\
\hline \multirow{2}{*}{ Coal } & 1000 & 300 & 550,000 & 400 & 0.70 & $2,380,000$ & 3.0 & 3.0 & 3.0 & 3.0 & 12 & 12,000 \\
\hline & 700 & 105 & 182,000 & 1300 & 0.16 & $1,670,000$ & 3.0 & 3.0 & 3.0 & 3.0 & 4 & 2800 \\
\hline \multirow{2}{*}{$\mathrm{CC}$} & 250 & 63 & 120,000 & 1400 & 1.66 & 378,000 & 5.0 & 5.0 & 1.5 & 1.5 & 74 & 18,500 \\
\hline & 100 & 30 & 104,000 & 900 & 0.73 & 151,000 & 5.0 & 5.0 & 1.5 & 1.5 & 21 & 2100 \\
\hline \multirow{2}{*}{ LNG } & 700 & 140 & 117,000 & 2400 & 0.40 & $1,060,000$ & 3.0 & 3.0 & 1.5 & 1.5 & 19 & 13,300 \\
\hline & 200 & 80 & 66,000 & 2200 & 2.50 & 302,000 & 3.0 & 3.0 & 1.5 & 1.5 & 13 & 2600 \\
\hline \multirow{4}{*}{ Oil } & 700 & 175 & 260,000 & 5000 & 0.38 & $1,060,000$ & 3.0 & 3.0 & 1.5 & 1.5 & 4 & 2800 \\
\hline & 500 & 100 & 200,000 & 5000 & 0.05 & 756,000 & 3.0 & 3.0 & 1.5 & 1.5 & 6 & 3000 \\
\hline & 250 & 50 & 316,000 & 4600 & 1.05 & 378,000 & 3.0 & 3.0 & 1.5 & 1.5 & 15 & 3750 \\
\hline & & & & & & & & & & Total & 168 & 60,850 \\
\hline
\end{tabular}

\subsubsection{Load Demand Data}

We employ the hourly actual data on the load demand of the Kanto area for two months from April 2 to 30 of 2016 and from January 2 to 30 of 2017 [34]. The data are linearly interpolated into the half-hourly values. As noted, we assume that the load demand can be perfectly forecasted in the previous day.

\subsubsection{PV Power Output Data}

We employ the datasets of the forecasted PV power output and the data on the estimated PV power output from April 1 to 30 of 2016, and from January 1 to 30 of 2017. The estimated PV power dataset is based on Ohtake et al. (2018) [35], and the forecasted PV power dataset is made by the same manner, except for the forecast input data which were presented in [36-38]. On the tilt angles of the PV systems, a flat angle is assumed because of no statistical information on tilt angles in Japan [35]. The PV power output was estimated by satellite estimated surface solar radiation data obtained from a geostationary satellite Himawari 8, which was presented in $[39,40]$, monitoring data. The detailed algorithm of estimation of the solar radiation from a satellite monitoring data was described in Takenaka et al. (2011) [41], which is called "AMATERASS" dataset. We received the AMATERASS dataset through the Solar Radiation Consortium [42]. PV power installation, solar radiation and PV module temperature are considered in our PV estimation algorithm for the regional area. The detail of the estimation method of the PV power generation was noted in the previous study [35]. Estimated output is considered as the actual PV power output in the simulations.

PV power forecast for each municipality was made from the operational weather prediction model, the meso-scale model (MSM) of the Japan Meteorological Agency [36] and PV installation capacity for each area. Each MSM forecast dataset was released every $3 \mathrm{~h}$ (00:30, 03:30, 06:30, 09:30, 12:30, 15:30, 18:30 and 21:30 UTC) and consists of the halfhourly forecasted values from the release time to $38.5 \mathrm{~h}$ ahead. The forecasted PV power output was calculated by AIST by the same manner of the estimated PV power output 
data noted in the previous paragraph. As the input data, solar irradiance forecasts (i.e., downward shortwave flux) by the MSM are used. Validation results of solar forecasts from the MSM are described in the previous studies using surface observation [37,38]. They indicate that MSM tends to under-forecast in the summer seasons and over-forecast in winter seasons because of the issues regarding the reproduction of cloud covers in the model. A bias correction has not been performed in this study for the PV power forecast. The total number of the datasets used in the simulations is $240(8 \times 30)$ for each month.

Both the forecasted and estimated data were obtained by the municipality based on the actual installed capacity in 2016. Hence, we total the data in the Kanto area, normalize them by the capacity, and convert them according to the installed PV capacity assumed in the simulations.

Figures 3 and 4 show the day-ahead (blue) and intra-day ahead (orange) mean bias errors (MBEs) and root mean square errors (RMSEs) between the forecasted and estimated PV power outputs from 7:00 to 15:00 LT (17 time periods of unit $0.5 \mathrm{~h}$ ) from April 2 to 30 of 2016 (29 days), and from January 2 to 30 of 2017 (29 days), respectively.

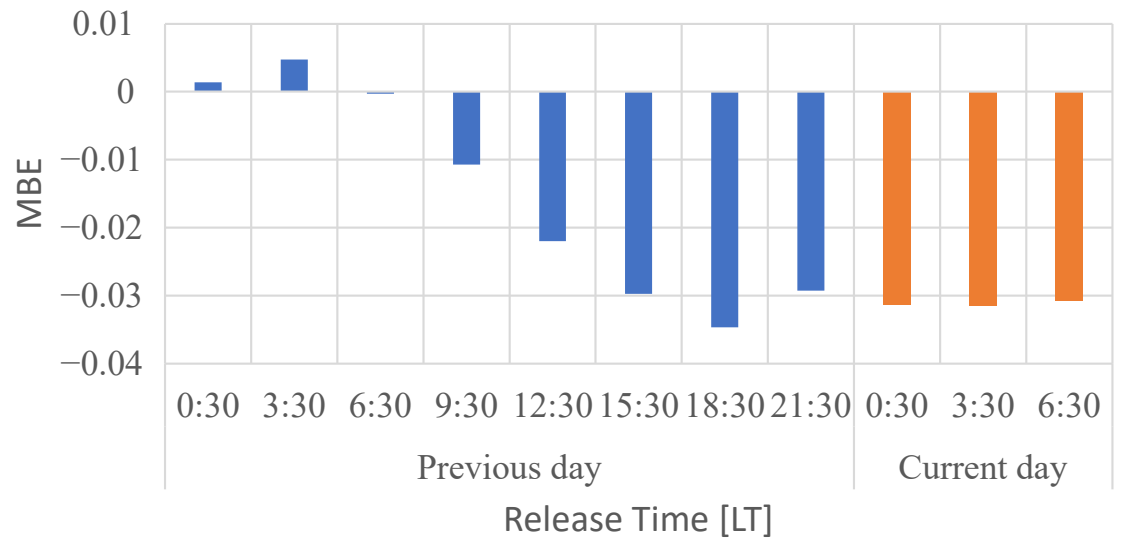

(a)

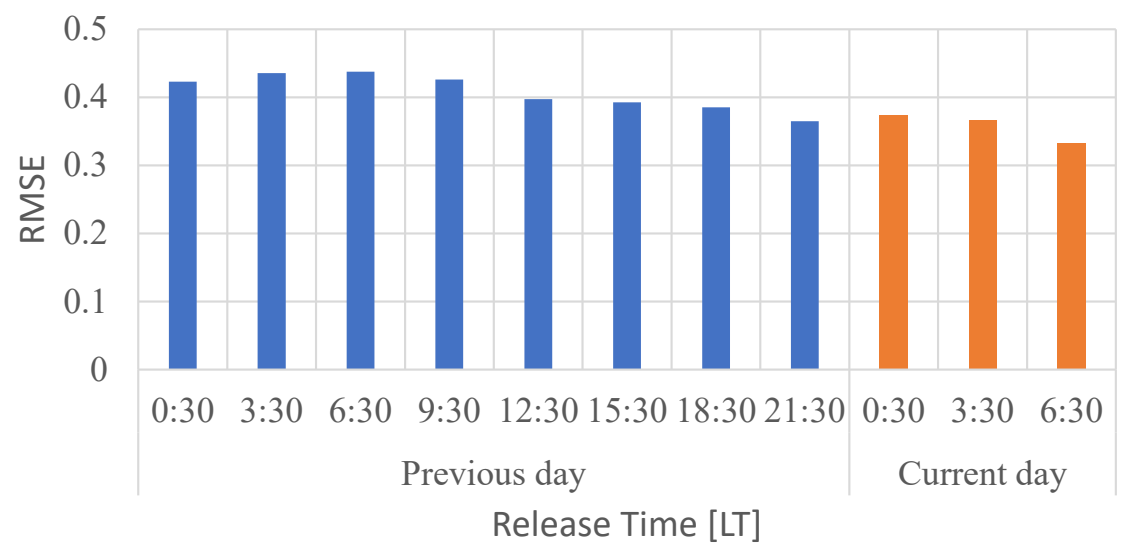

(b)

Figure 3. Error analysis from April 2 to 30. (a) Mean bias error (MBE) of the day-ahead and intraday PV power forecasts. (b) RMSE of the day-ahead and intraday PV power forecasts.

The unit of the horizontal axis is release time (local time, LT), whereas that of the vertical axis is the MBE or RMSE normalized by the installed PV capacity (GW). They show the averaged values per hour. The hourly MBE and RMSE in units of GWh in the area can be obtained by multiplying the total installed PV capacity. MBE and RMSE are calculated at each release time (RT) by 


$$
M B E=\sum_{d=2}^{30} \sum_{t=14}^{30}\left(\frac{p_{d, t, R T}^{f}-p_{d, t}^{a}}{29 * 17}\right),
$$

and

$$
R M S E=\sum_{d=2}^{30} \sum_{t=14}^{30} \sqrt{\frac{\left(p_{d, t, R T}^{f}-p_{d, t}^{a}\right)^{2}}{29 * 17}},
$$

respectively.

Most of the MBEs are negative, which indicates that the PV power outputs tended to be under forecasted. The forecasts seem improved with time because the RMSEs tend to become small with the release time. The RMSE values in Figure $3 b$ are larger than those in Figure $4 \mathrm{~b}$ because of high solar irradiance in April.

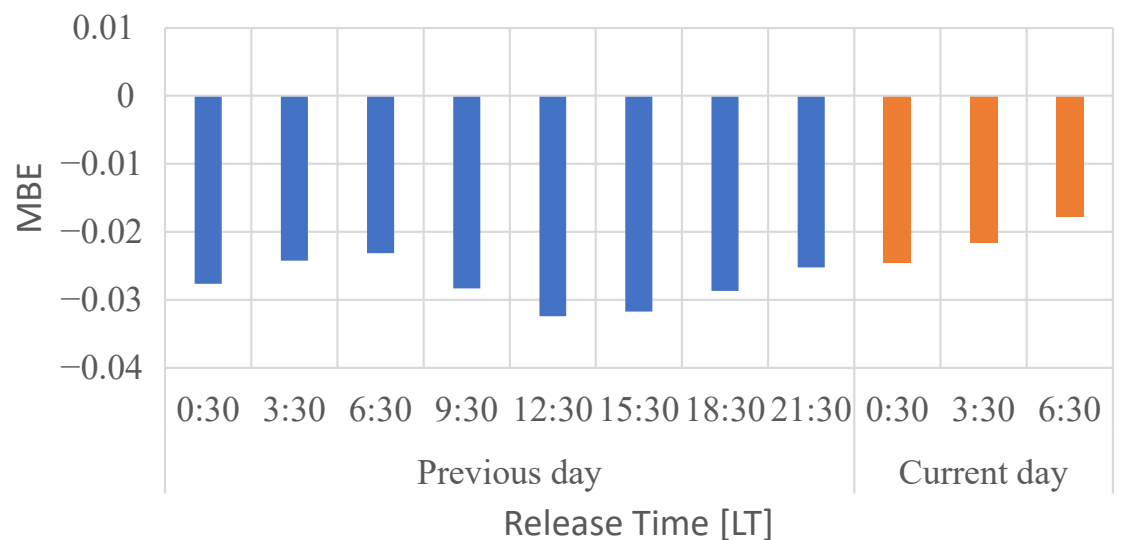

(a)

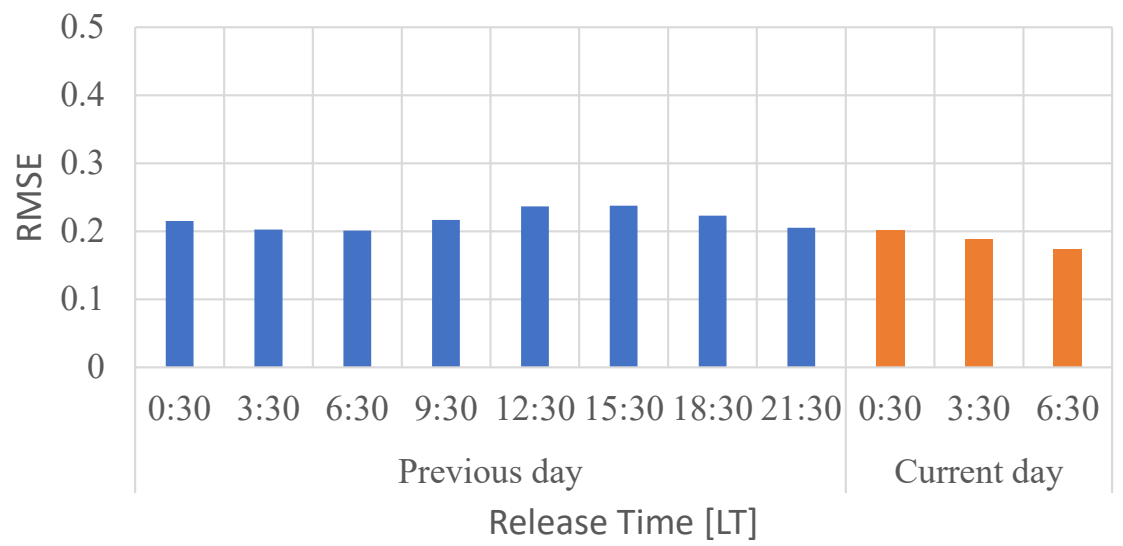

(b)

Figure 4. Error analysis from January 2 to 30. (a) MBE of the day-ahead and intraday PV power forecasts. (b) RMSE of the day-ahead and intraday PV power forecasts.

\subsection{Simulation Results}

\subsubsection{Total Imbalance and Cost}

Figures 5 and 6 show the daily-averaged total curtailed PV energy, total energy shortfall, total operational costs of thermal generators and total energy loss for installed PV capacity of $50 \mathrm{GW}$ and $100 \mathrm{GW}$, respectively, for the simulation period from April 2 to 30 ( 29 days). Figures 7 and 8 plot the same details for the simulation period from January 2 to 30 (29 days). 
According to Figures 5a, 6a, 7a and 8a, the total curtailed PV energy decreases with the increase of BESS capacity. The total curtailed PV energies in Figures 7a and 8a are much smaller than those in Figures 5a and 6a, respectively, because of lower solar irradiance. The amounts without BESS in Case 2 in Figures $7 \mathrm{a}$ and $8 \mathrm{a}$ are $11 \%$ and $39 \%$ of those in Figures $5 \mathrm{a}$ and $6 \mathrm{a}$, respectively. The PV curtailment can be completely avoided in Case 2 with 200 GWh BESS in Figure 7a. The proposed scheduling method (Case 2) reduces the PV curtailment compared to convectional scheduling (Case 1). The effectiveness of the Case 2 method becomes large with the increase of BESS capacity. According to our study, the PV curtailment for months with lower solar irradiance can be reduced to almost zero with BESS. Similarly, in a study by Wang et al. [23], the wind power curtailment has been reduced to zero with the energy storage by increasing the operational cost. In our study, the PV curtailment for months with higher solar irradiance can be unavoidable even with BESS. It is because the energy surplus cannot always be charged (or discharged) because of the SoC constraint when the installed PV capacity is so large, which will be presented in detail in Section 3.2.2.

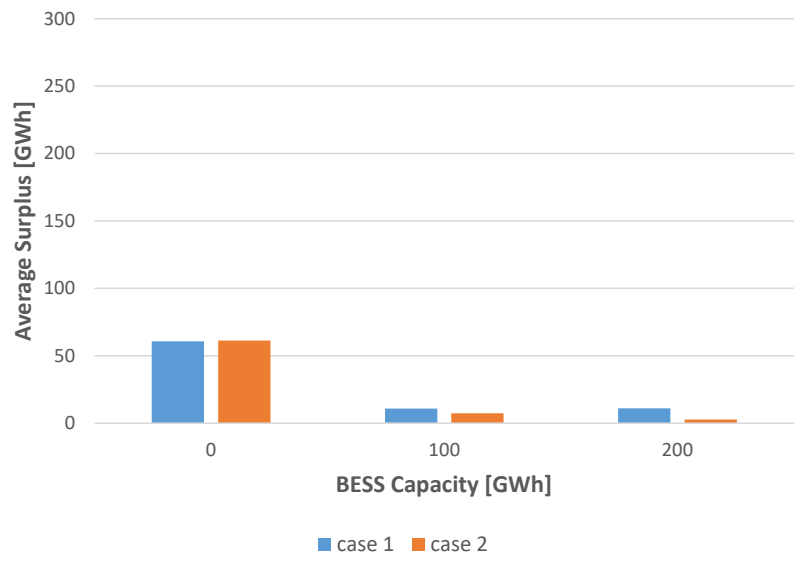

(a) Average curtailed PV energy (PV: 50 GW)

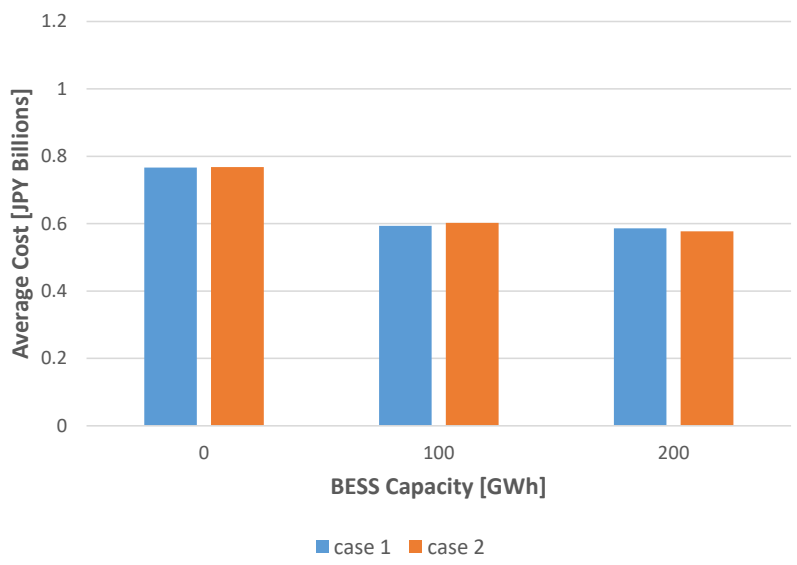

(c) Average operational cost of thermal generators

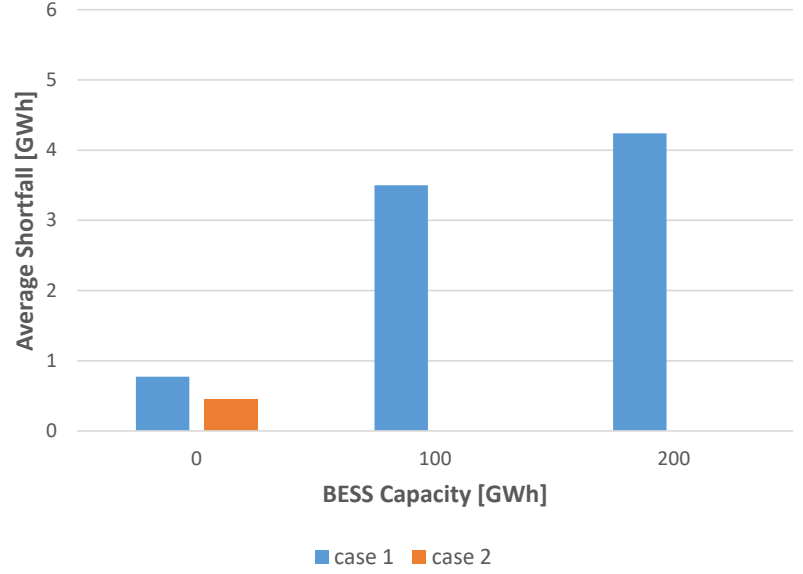

(b) Average energy shortfall (PV: $50 \mathrm{GW})$

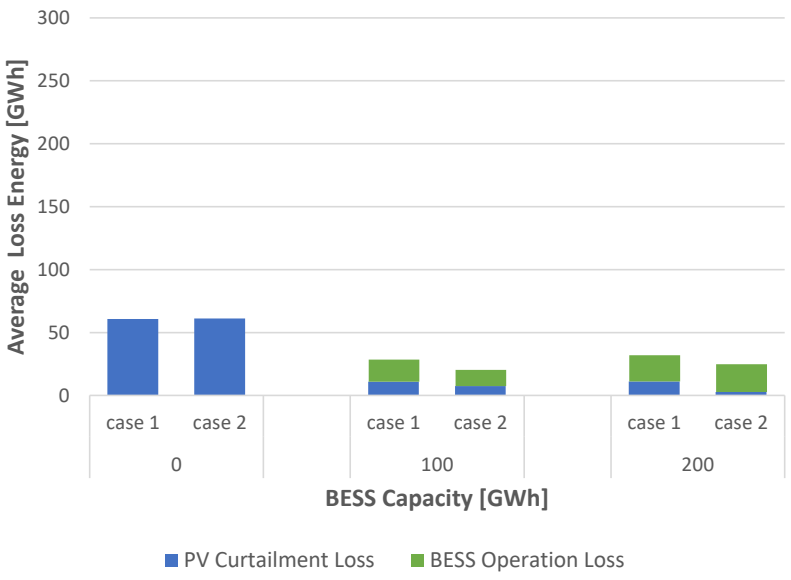

(d) Average energy loss (PV curtailment and BESS)

Figure 5. The simulation results averaged per day with installed PV capacity of 50 GW for Case 1 and Case 2 with BESS capacities of 0, 100 and $200 \mathrm{GWh}$ for the simulation period from April 2 to 30 (29 days). 
Figures $5 b, 6 b, 7 b$ and $8 b$ show that the total energy shortfall in Case 1 for the period increases with BESS capacity. This is due to the BESS charges just following the schedule even if the actual PV power output is much smaller than the forecasted PV power output. The amounts of the energy shortfall in Case 1 in Figures $5 b$ and $8 b$ tend to be smaller than those in Figures $5 b$ and $6 b$ because of lower solar irradiance. In Figures $5 b, 6 b, 7 b$ and $8 b$, the proposed algorithm (Case 2) with the BESS completely eliminates the power shortfalls for all cases with the immediate discharge and the schedule update.

The operational cost becomes smaller with larger BESS capacity in Figures $5 c, 6 c, 7 c$ and $8 \mathrm{c}$. It is because the net load demand is flattened with a large value of the BESS capacity. The cost difference between the two cases is very small when the installed BESS capacity is zero or 100 GWh. The cost with 200 GWh BESS in Case 2 is noticeably smaller than that in Case 1. We have only plotted the operational costs in thermal generators. The reduction of the cost would be more significant if the energy curtailment and shortfall costs are taken into account. The cost with 100 GWh BESS is almost the same as that with 200 GWh BESS in Figure 7c because 100 GWh BESS can significantly reduce the PV curtailment as shown in Figure 7a. The costs in Figures $7 c$ and $8 c$ tend to be higher than those in Figures $5 c$ and $6 c$ because less PV energy is available in January with lower solar irradiance as well as the load demand in January is heavier.

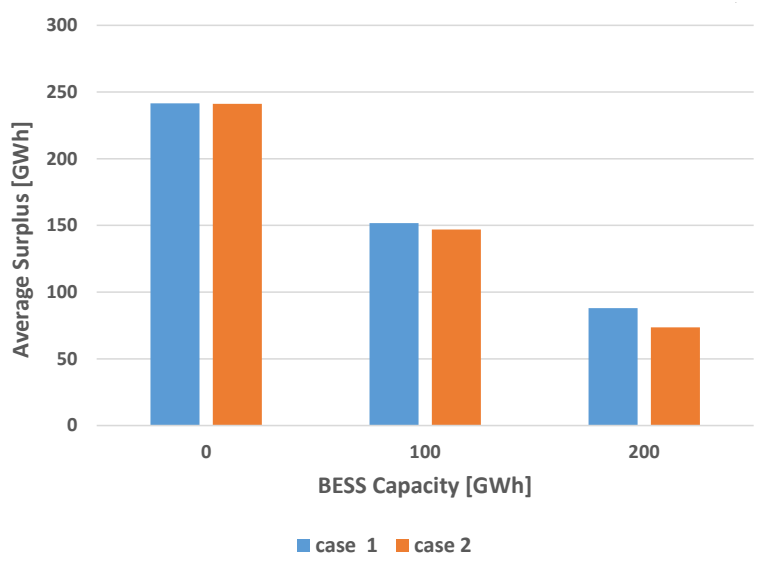

(a) Average curtailed PV energy (PV: 100 GW)

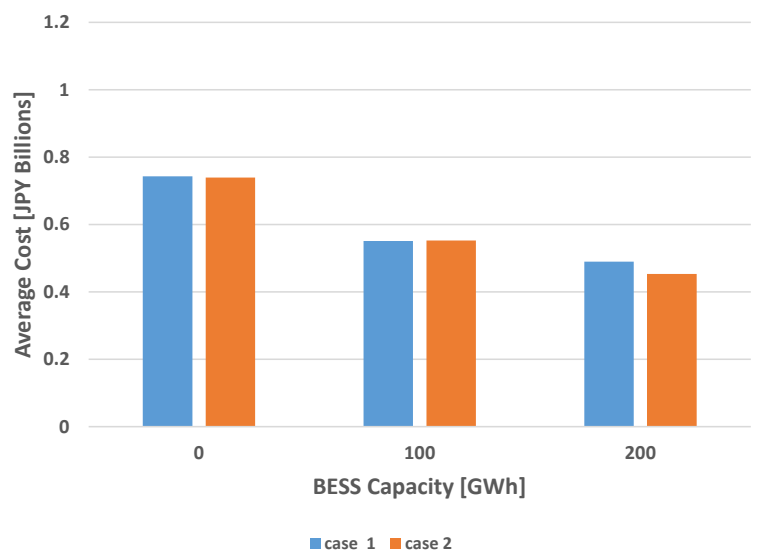

(c) Average operational cost of thermal generators

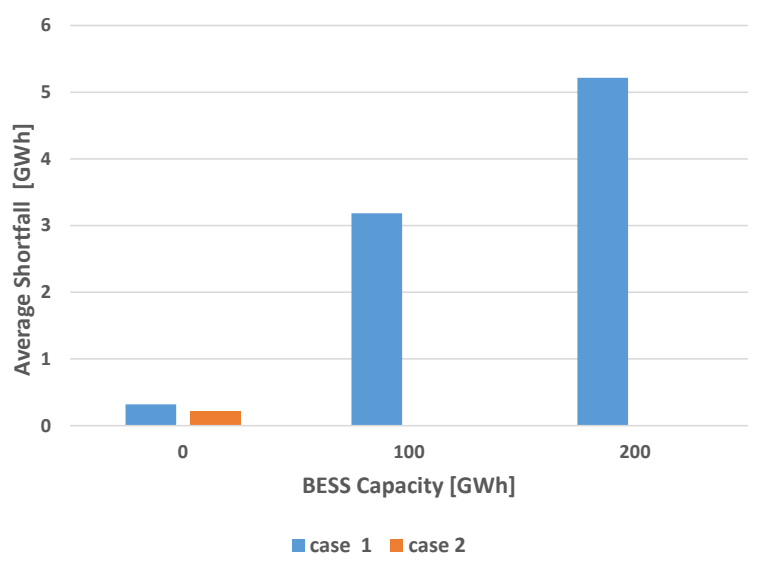

(b) Average energy shortfall (PV: 100 GW)

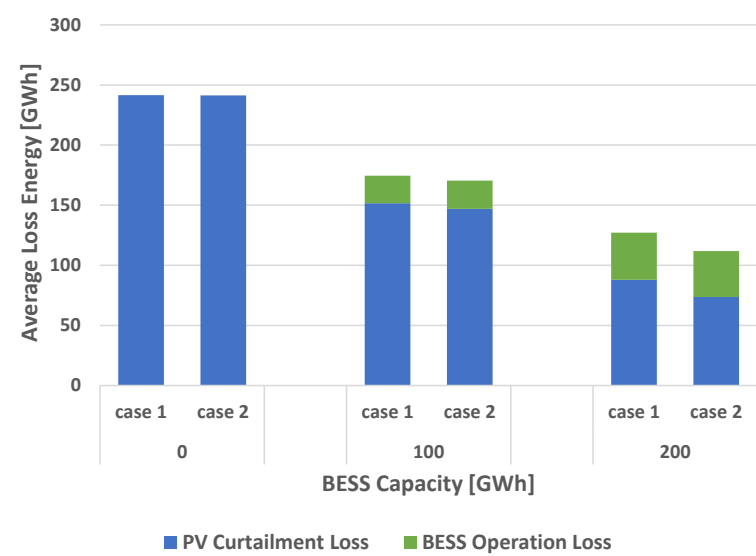

(d) Average energy loss (PV curtailment and BESS)

Figure 6. The simulation results averaged per day with installed PV capacity of $100 \mathrm{GW}$ for Case 1 and Case 2 with BESS capacities of 0, 100 and 200 GWh for the simulation period from April 2 to 30 (29 days). 
The total energy losses shown in Figures $5 d, 6 d, 7 d$ and $8 d$ are the sum of the curtailed PV energy (blue) and the BESS (green) charge/discharge energy loss. With the BESS operation, it is important to reduce the total loss as well as the curtailed PV energy. The total energy loss becomes small with larger BESS capacity except for Figure 7d where the PV curtailment without BESS is quite small. When the BESS is used, the energy loss in Figure $7 \mathrm{~d}$ mostly consists of the loss due to BESS charge/discharge. That is because the PV curtailment can be reduced to almost zero with 100 GWh BESS as well as 200 GWh BESS as shown in Figure 7a. The total energy loss in Case 2 tends to be smaller than that in Case 1 for each BESS capacity in Figures $5 d, 6 d, 7 d$ and $8 d$, respectively. However, the energy loss due to charging and discharging in Case 2 is not always smaller than that in Case 1 (e.g., Figure 7d). It is because the objective function for the schedule update and operation is set not for minimizing the total energy loss but for minimizing the operational cost of the thermal generators. Therefore more charging and discharging occur with 200 GWh BESS capacity. As a result, the cost with 200 GWh BESS is smaller than that with 100 GWh BESS as shown in Figures $5 c$ and $7 c$ although the total BESS charge/discharge loss is larger.

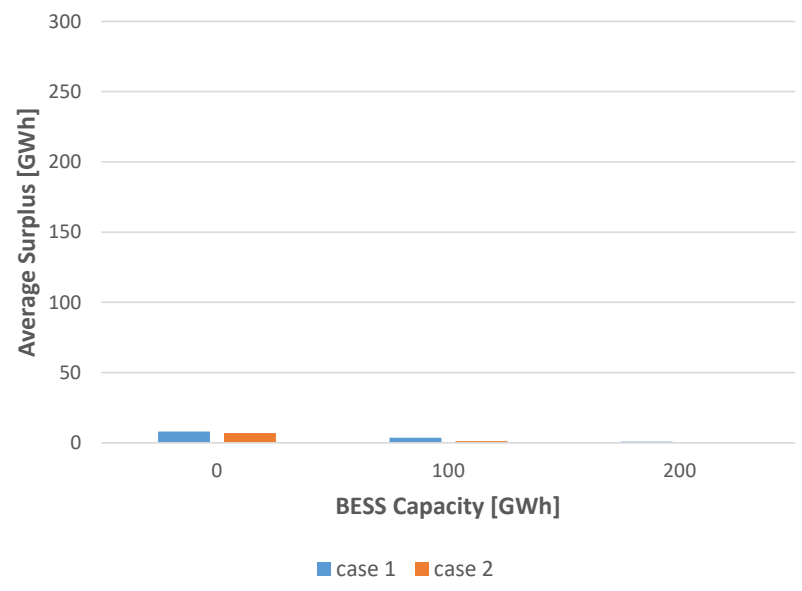

(a) Average curtailed PV energy (PV: 50 GW)

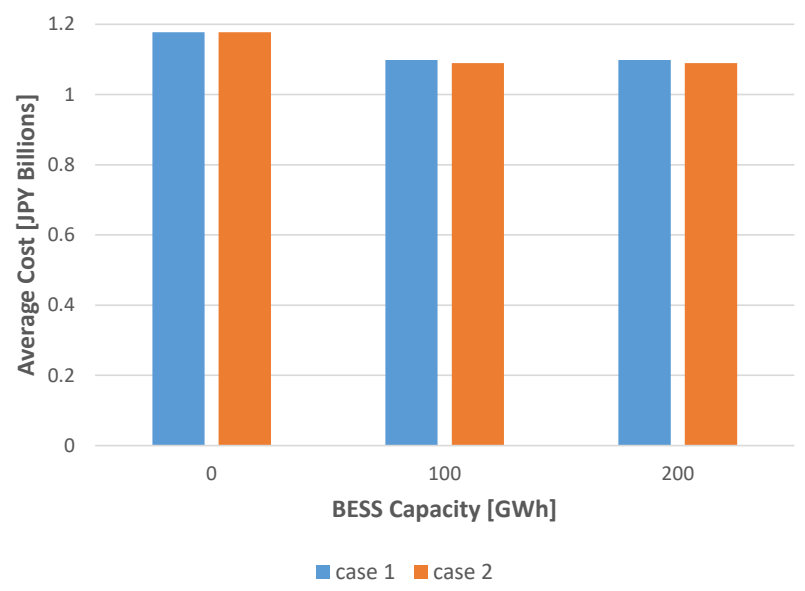

(c) Average operational cost of thermal generators

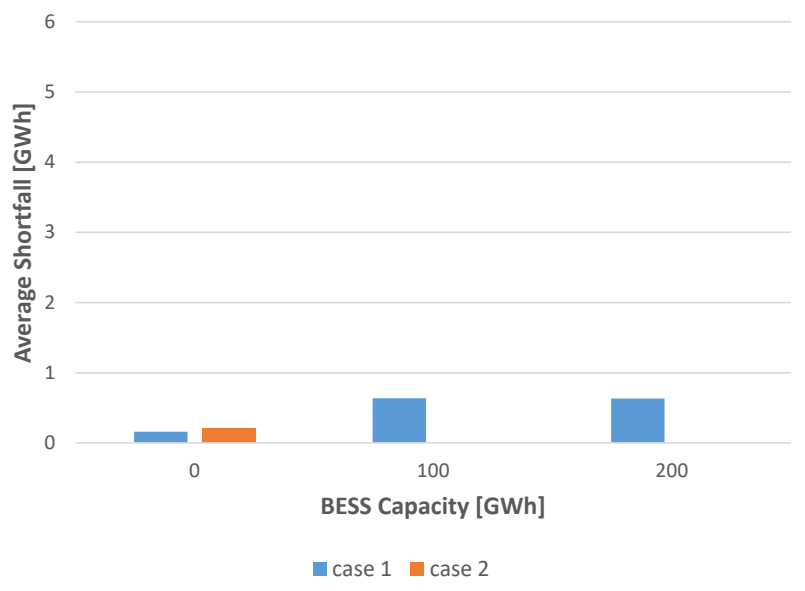

(b) Average energy shortfall (PV: $50 \mathrm{GW})$

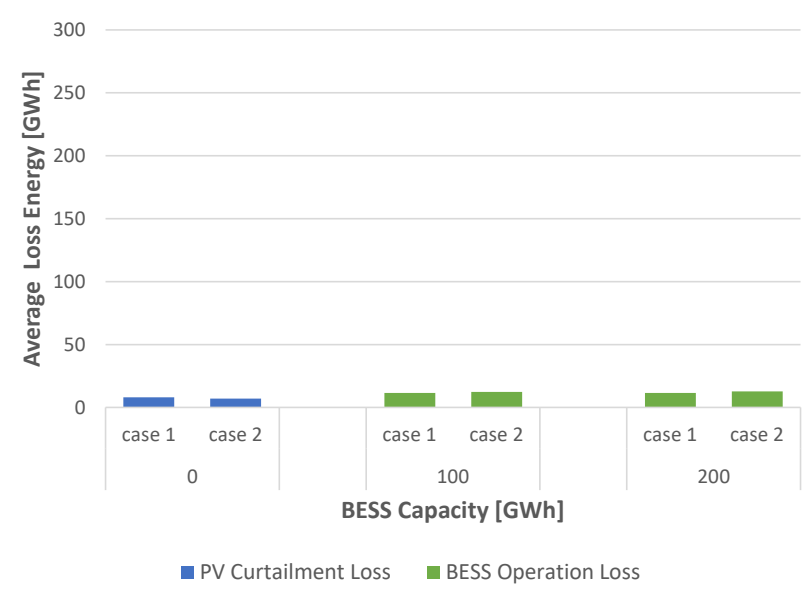

(d) Average energy loss (PV curtailment and BESS)

Figure 7. The simulation results averaged per day with installed PV capacity of 50 GW for Case 1 and Case 2 with BESS capacities of 0, 100 and 200 GWh for the simulation period from January 2 to 30 (29 days). 
Table 3 summarizes the impact of the proposed method on the PV curtailment reduction in different two months. The total energy demand, the average demand, the total PV energy production, the average PV power, the total curtailed PV energy, the PV curtailment ratio and the PV curtailment reduction ratio are shown for each installed PV and BESS capacities.

The energy demand in January is approximately $25 \%$ larger than that in April, whereas the PV energy production in January is approximately 30\% smaller than that in April. Therefore, the curtailed PV energy in January is smaller than that in April. The PV curtailment ratio is obtained by dividing the total curtailed PV energy by the total PV energy production. When the installed PV capacity is $100 \mathrm{GW}$, the PV curtailment ratio decreases from $55.1 \%$ (without BESS) to $16.8 \%$ (with 200 GWh BESS) in April whereas it decreases from $34.0 \%$ (without BESS) to $2.6 \%$ (with 200 GWh BESS) in January. The PV curtailment reduction ratio with BESS is obtained by dividing the reduced PV curtailment with the BESS by the curtailed PV energy without the BESS. When the installed PV capacity is $100 \mathrm{GW}$, the curtailment reduction ratio ranges from 39.1\% (with $100 \mathrm{GWh}$ BESS) to $69.5 \%$ (with 200 GWh BESS) in April whereas it ranges from 88.9\% (with 100 GWh BESS) to $95.2 \%$ (with 200 GWh BESS) in January.

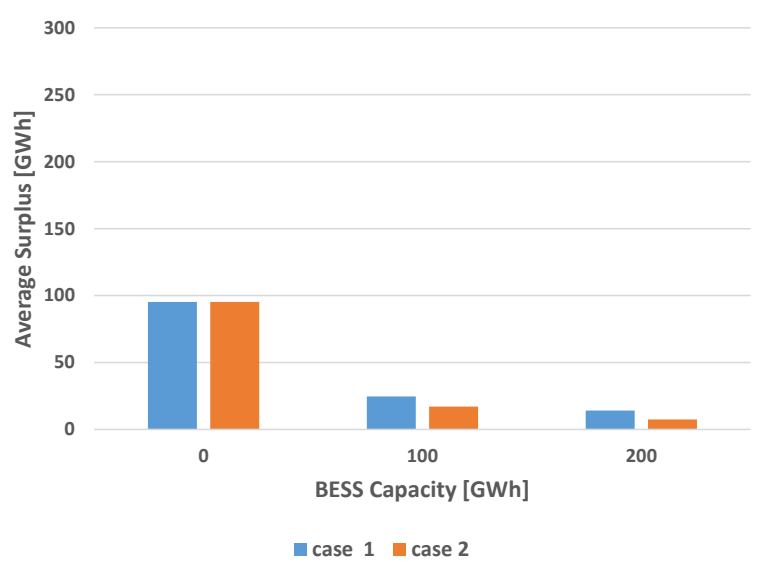

(a) Average curtailed PV energy (PV: 100 GW)

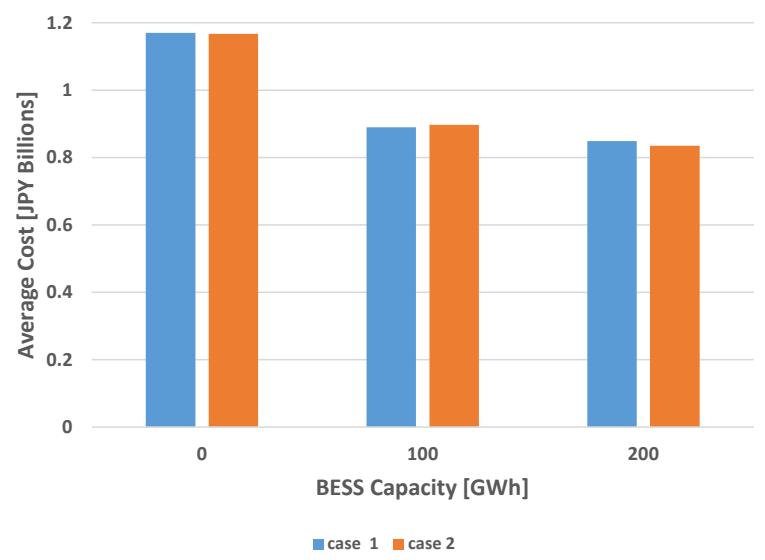

(c) Average operational cost of thermal generators

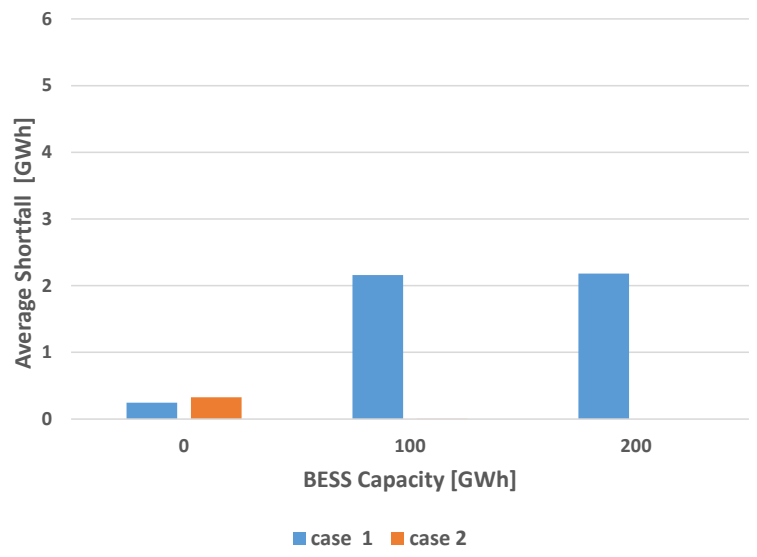

(b) Average energy shortfall (PV: 100 GW)

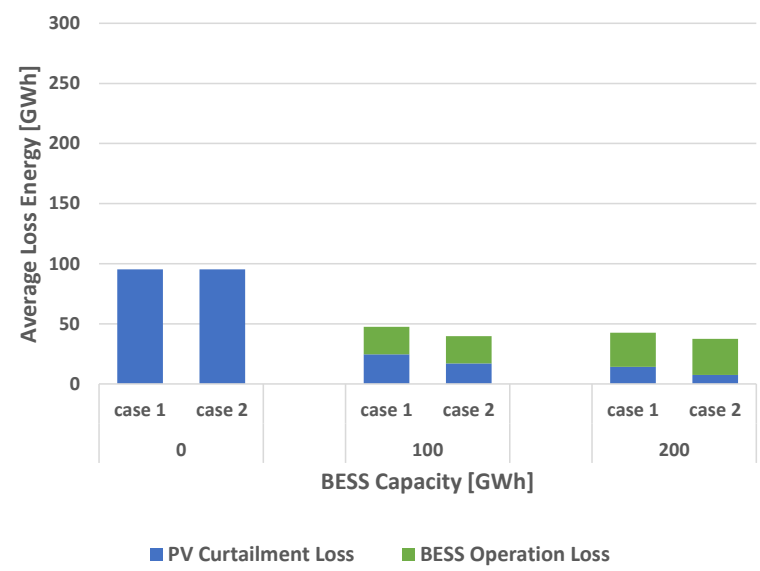

(d) Average energy loss (PV curtailment and BESS)

Figure 8. The simulation results averaged per day with installed PV capacity of $100 \mathrm{GW}$ for Case 1 and Case 2 with BESS capacities of 0,100 and $200 \mathrm{GWh}$ for the simulation period from January 2 to 30 (29 days). 
Table 3. Result comparison between April and January.

\begin{tabular}{|c|c|c|c|c|c|c|c|}
\hline & Installed PV capacity (GW) & & 50 & & & 100 & \\
\hline & Installed BESS capacity (GWh) & 0 & 100 & 200 & 0 & 100 & 200 \\
\hline \multirow{7}{*}{$\begin{array}{l}\text { April } \\
(2-30)\end{array}$} & $\begin{array}{l}\text { Total energy demand (GWh) } \\
\text { (Daily average) }\end{array}$ & \multicolumn{6}{|c|}{694} \\
\hline & Hourly average demand (GW) & \multicolumn{6}{|c|}{28.9} \\
\hline & $\begin{array}{l}\text { Total PV energy production (GWh) } \\
\text { (Daily average before curtailment) }\end{array}$ & \multicolumn{3}{|c|}{219} & \multicolumn{3}{|c|}{438} \\
\hline & $\begin{array}{l}\text { Hourly average PV power from } 7 \text { to } 15 \mathrm{~h} \text { (GW) } \\
\text { (Before curtailment) }\end{array}$ & \multicolumn{3}{|c|}{22.5} & \multicolumn{3}{|c|}{45.1} \\
\hline & $\begin{array}{c}\text { Total curtailed PV energy (GWh) } \\
\text { (Daily average for Case } 2 \text { ) }\end{array}$ & 61.2 & 7.4 & 2.7 & 241 & 147 & 73.6 \\
\hline & $\begin{array}{c}\text { PV curtailment ratio ( \% ) } \\
\text { (Case } 2)\end{array}$ & 28.0 & 3.4 & 1.2 & 55.1 & 33.6 & 16.8 \\
\hline & $\begin{array}{l}\text { PV curtailment reduction ratio ( } \% \text { ) } \\
\text { (Case } 2 \text { with BESS) }\end{array}$ & - & 88.0 & 95.7 & - & 39.1 & 69.5 \\
\hline \multirow{7}{*}{$\begin{array}{l}\text { January } \\
(2-30)\end{array}$} & $\begin{array}{l}\text { Total energy demand (GWh) } \\
\text { (Daily average) }\end{array}$ & \multicolumn{6}{|c|}{866} \\
\hline & Hourly average demand (GW) & \multicolumn{6}{|c|}{36.1} \\
\hline & $\begin{array}{l}\text { Total PV energy production (GWh) } \\
\text { (Daily average for before curtailment) }\end{array}$ & \multicolumn{3}{|c|}{140} & \multicolumn{3}{|c|}{280} \\
\hline & $\begin{array}{l}\text { Hourly average PV power from } 7 \text { to } 15 \mathrm{~h}(\mathrm{GW}) \\
\text { (Before curtailment) }\end{array}$ & \multicolumn{3}{|c|}{15.6} & \multicolumn{3}{|c|}{31.2} \\
\hline & $\begin{array}{c}\text { Total curtailed PV energy (GWh) } \\
\text { (Daily average for Case 2) }\end{array}$ & 6.9 & 0.0 & 0.0 & 95.3 & 17.1 & 7.4 \\
\hline & $\begin{array}{c}\text { PV curtailment ratio ( \% ) } \\
\text { (Case 2) }\end{array}$ & 5.0 & 0.0 & 0.0 & 34.0 & 6.1 & 2.6 \\
\hline & $\begin{array}{l}\text { PV curtailment reduction ratio ( \% ) } \\
\text { (Case } 2 \text { with BESS) }\end{array}$ & - & 99.9 & 100 & - & 88.9 & 95.2 \\
\hline
\end{tabular}

\subsubsection{Daily generation curves}

Figure 9 shows the difference between actual PV output and forecasted output at different releases on April 5, which are normalized by the installed PV capacity (GW). From this figure, it is obvious that the PV values are over forecasted and the forecast error gets reduced with shorter range forecast (from day-ahead forecast to intraday forecasts). Figures 10-13 show the daily generation curves in Cases 1 and 2 on April 5 th for installed PV capacities 50 and $100 \mathrm{GW}$. The unit of the horizontal axis is time (h). The black solid line represents the load and the purple solid line represents the charging power. The summation of hydro and nuclear power generation is represented by the orange area. Thermal output, actual PV power, BESS discharging power, PV curtailment and power shortfall are represented by blue, green, yellow, brown, and gray areas respectively. This day was chosen as an example for a day with the larger shortfall. 


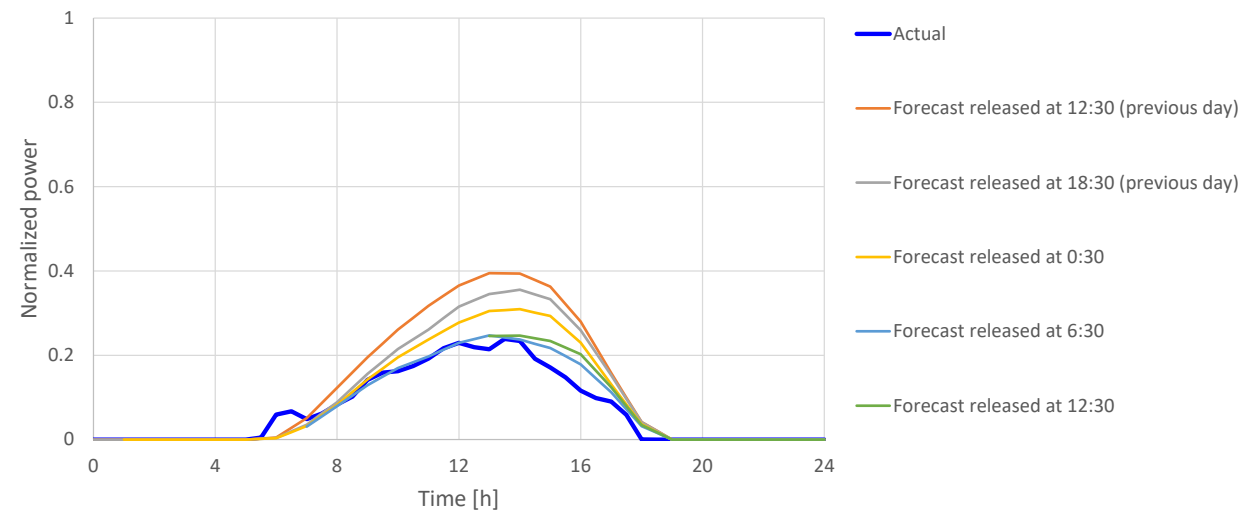

Figure 9. PV power output on April 5.

In Figure 10a, the shortfall occurs at around $10 \mathrm{~h}$ and $16 \mathrm{~h}$ because the forecasted PV power output is larger than the actual output (over forecasted). The thermal generator output is flattened in Figure $10 \mathrm{~b}, \mathrm{c}$, which corresponds to the flattening of the netload. The shortfall with the BESS can be seen from 10 to $15 \mathrm{~h}$ in Figure 10b,c because the BESS is charging during the period just following the day-ahead schedule based on the overforecast error.

The amount of shortfall in Figure 11a is smaller than that in Figure 10a due to the UC update. No shortfall can be seen in Figure 11b,c. The BESS gets discharged rapidly to avoid the shortfall and then the charge power is adjusted by the new BESS schedule update. Figure $11 \mathrm{~b}$ is similar to Figure 11c because the actual PV power output is very small on that day.

The amount of the shortfall in Figure 12 increases with a larger value of the BESS capacity because the net load is flattened with larger BESS capacity. The trend of Figure 13 is similar to Figure 11. The shortfalls are completely reduced in Figure $13 \mathrm{~b}, \mathrm{c}$ where the BESS charging schedules are modified.

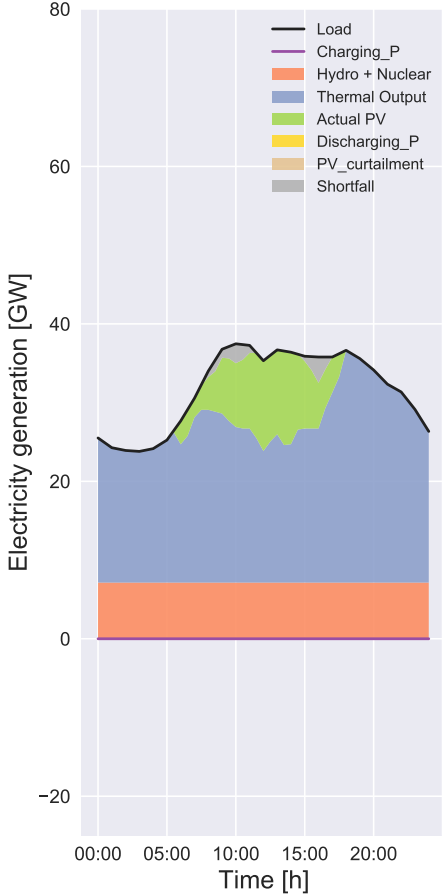

(a) 0 GWh BESS

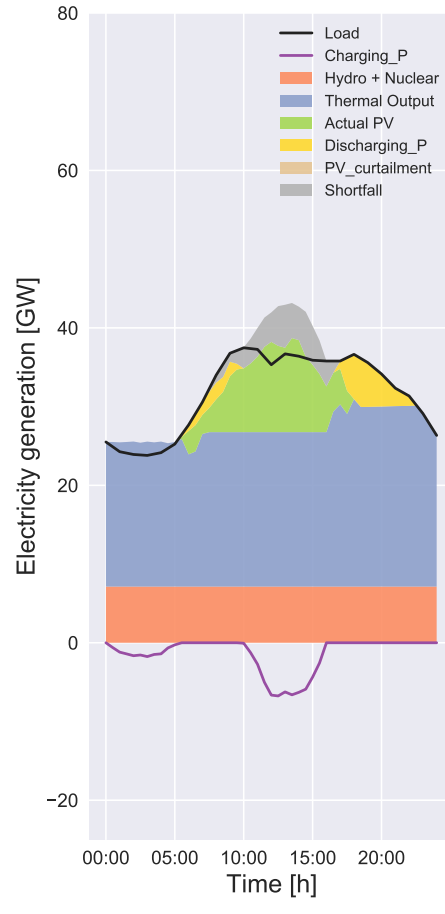

(b) 100 GWh BESS

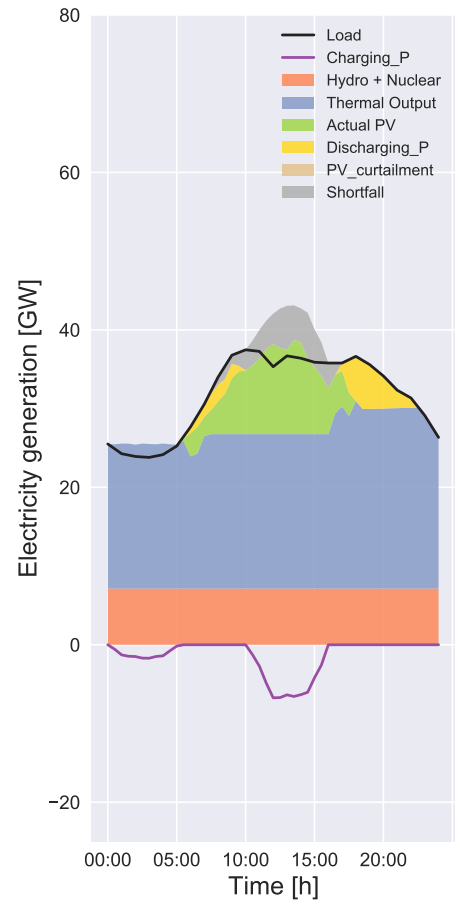

(c) 200 GWh BESS

Figure 10. Daily generation curve on April 5 (Case 1, PV: 50 GW). 
Figure 14 shows the actual and forecasted PV power output on April 10th, which are normalized by the installed PV capacity (GW). The PV power output tended to be under forecasted. Figures 15-18 show the daily generation curves in Cases 1 and 2 on April 10th for installed PV capacities are 50 and $100 \mathrm{GW}$. This day was selected as an example for a day with large PV curtailment.

In Figure 15a, the PV power output exceeds the load demand and is curtailed because the operating thermal generator outputs are reduced considerably. Most of the power surplus is used for charging in Figure 15b,c. However, the PV curtailment can be seen because the day-ahead forecasted PV power output tends to be smaller than the actual output (under forecast) from the morning till $13 \mathrm{~h}$. The shortfall occurs at $15 \mathrm{~h}$ with 200 GWh BESS because the forecasted PV power output is larger than the actual output at around that time as shown in Figure 14. The BESS discharges during $0-5 \mathrm{~h}$ and $16-23 \mathrm{~h}$.

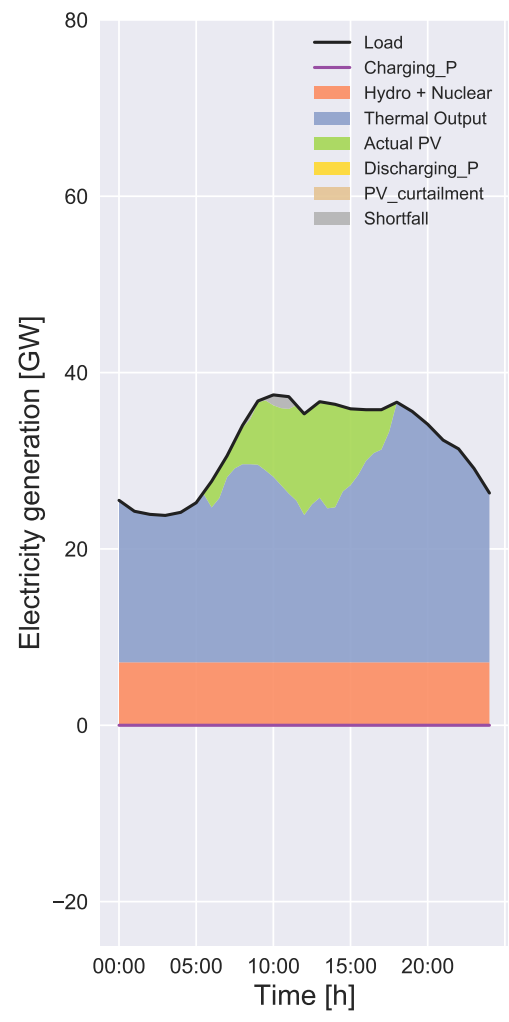

(a) 0 GWh BESS

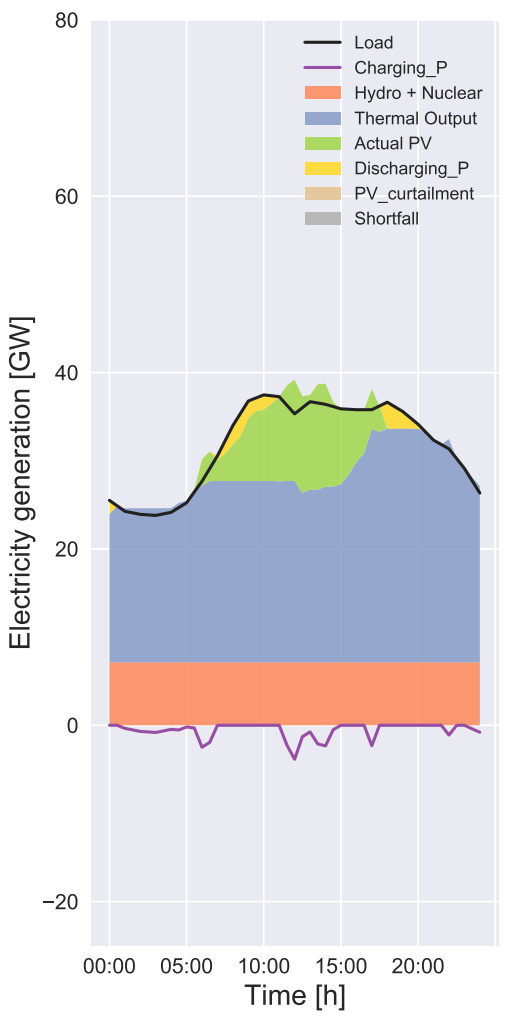

(b) 100 GWh BESS

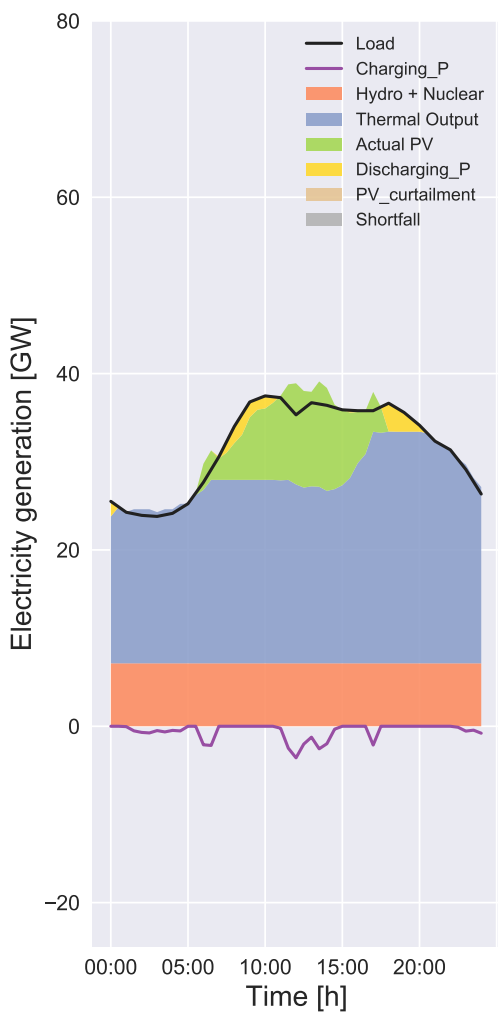

(c) 200 GWh BESS

Figure 11. Daily generation curve on April 5 (Case 2, PV: 50 GW). 


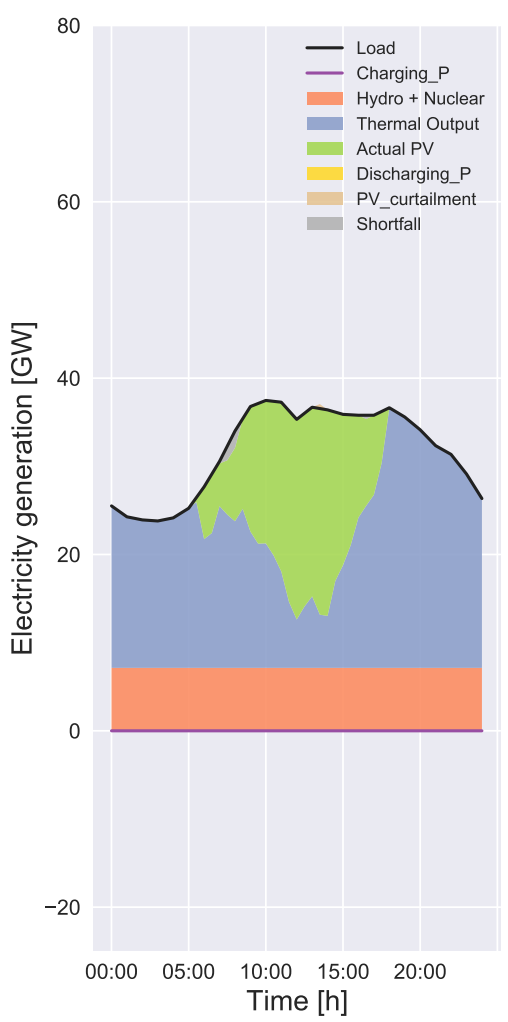

(a) 0 GWh BESS

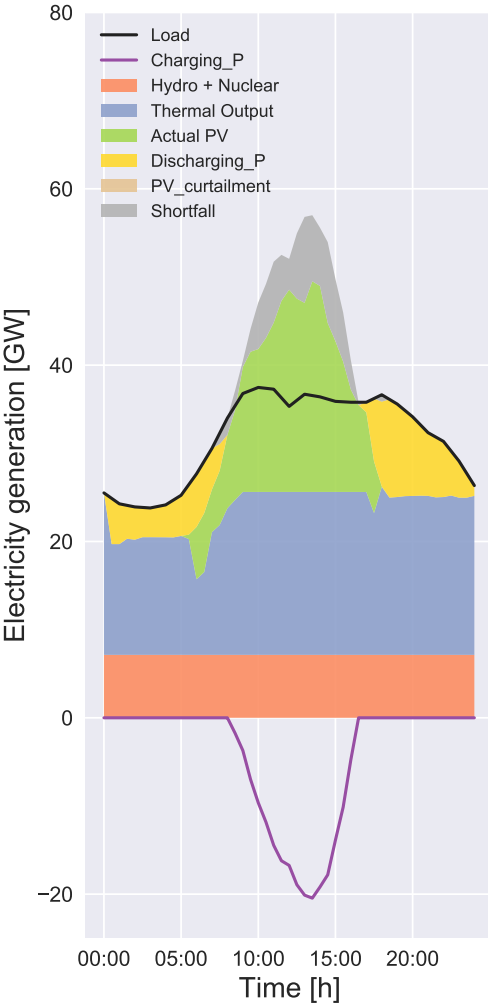

(b) 100 GWh BESS

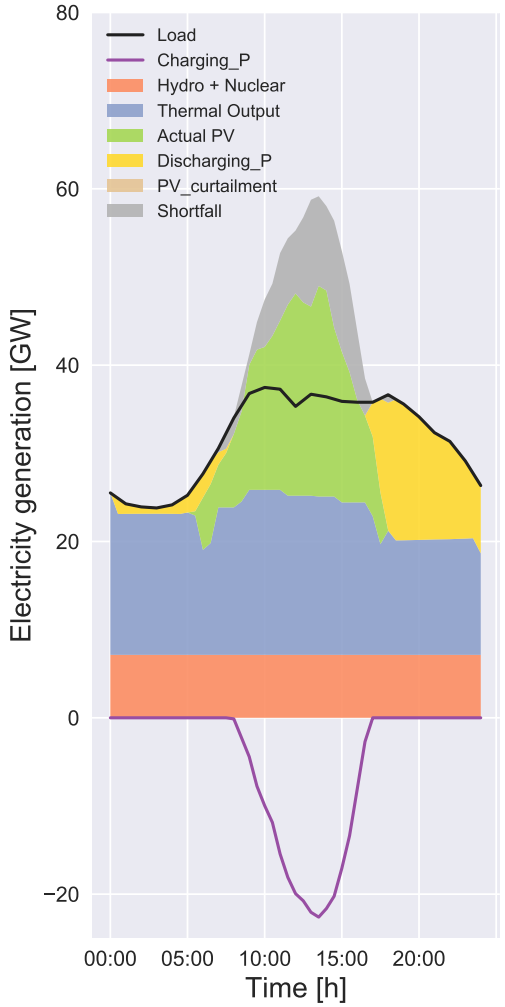

(c) 200 GWh BESS

Figure 12. Daily generation curve on April 5 (Case 1, PV: 100 GW).

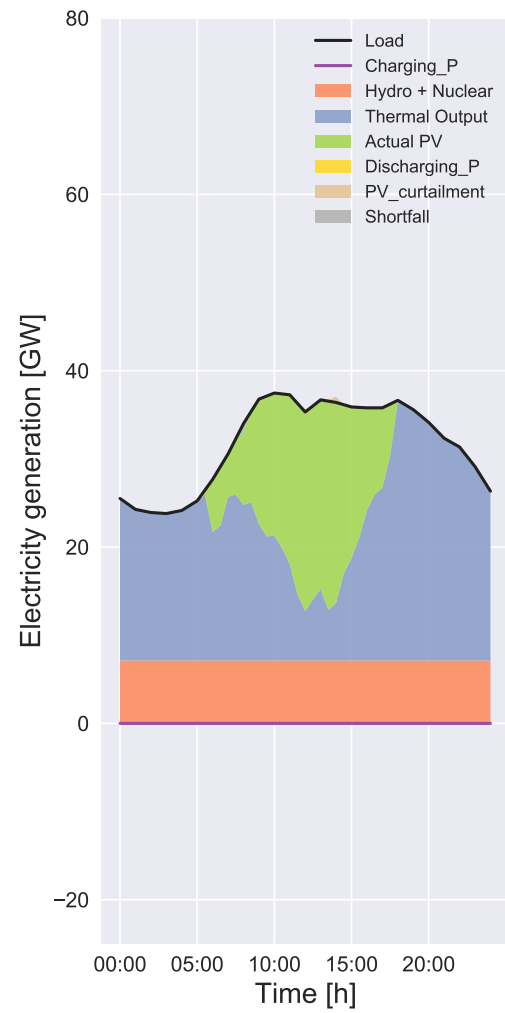

(a) 0 GWh BESS

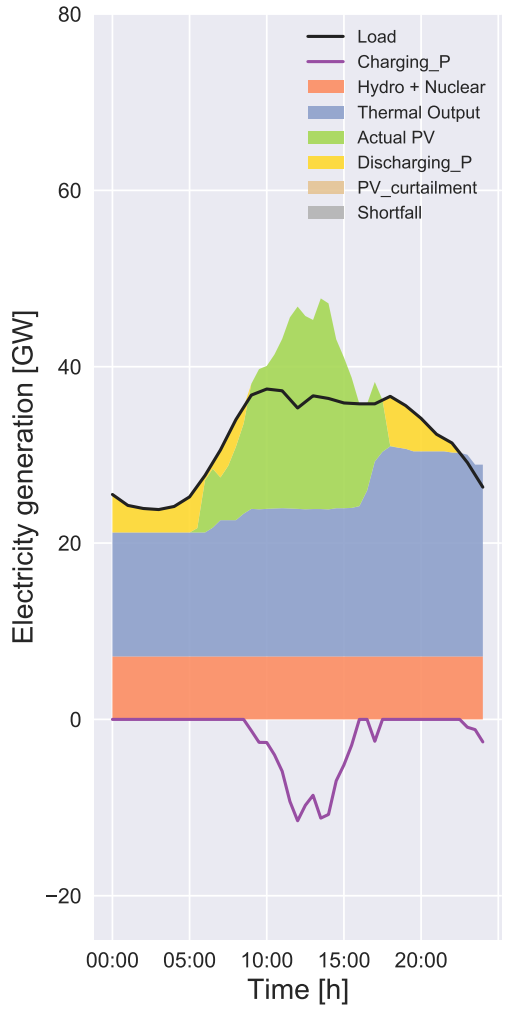

(b) 100 GWh BESS

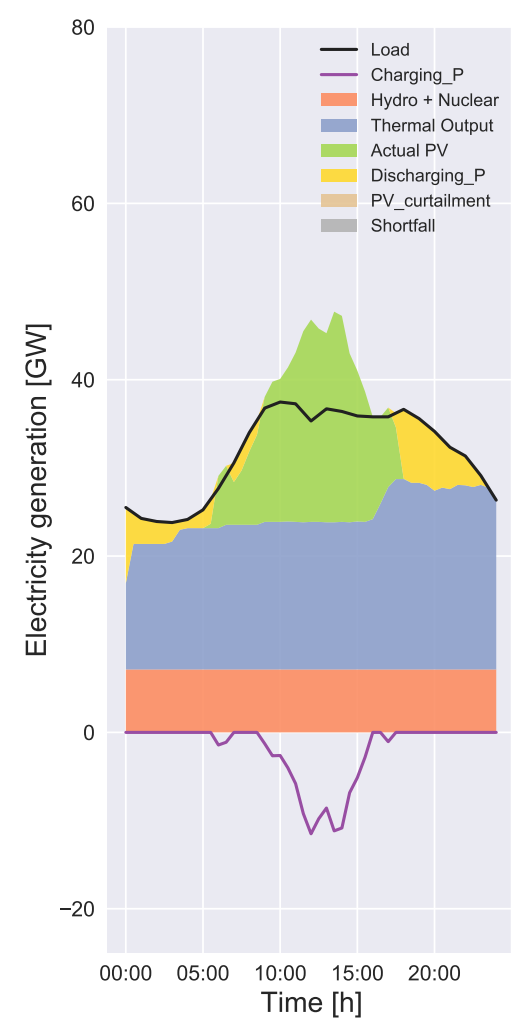

(c) 200 GWh BESS

Figure 13. Daily generation curve on April 5 (Case 2, PV: 100 GW). 


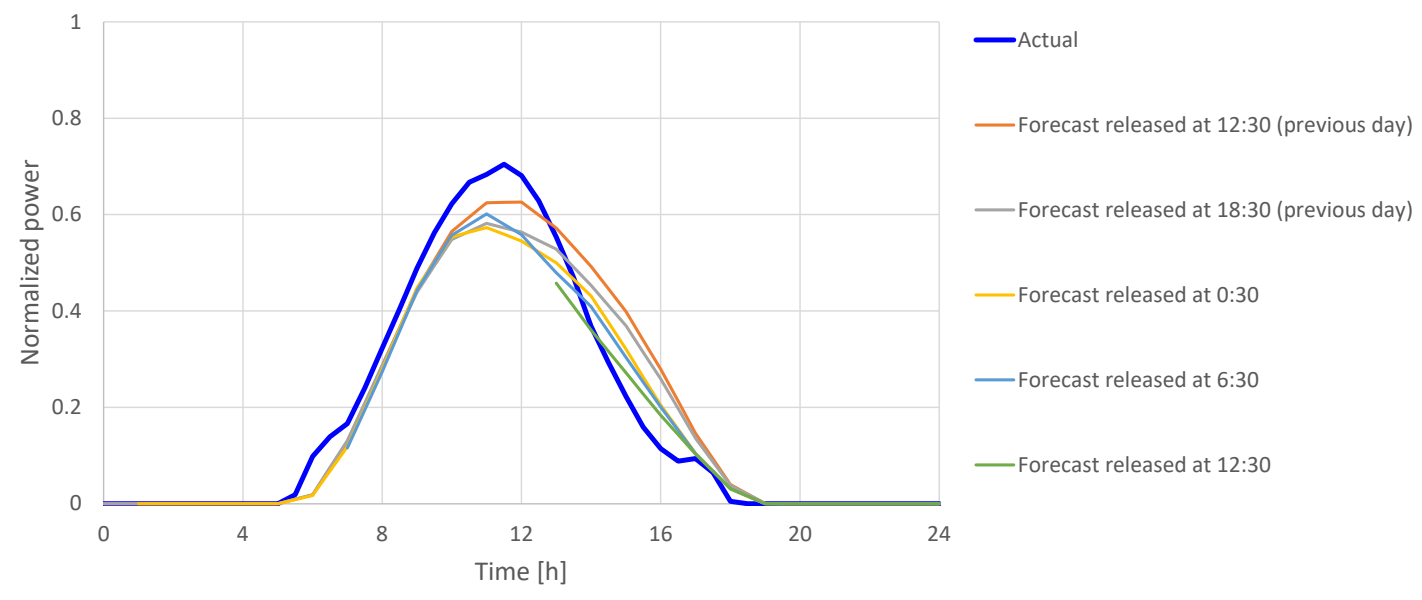

Figure 14. PV power output on April 10.

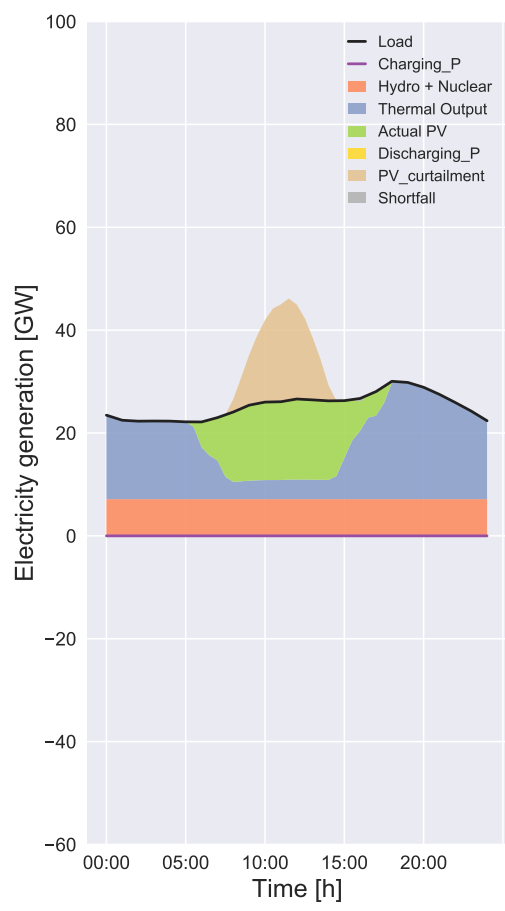

(a) 0 GWh BESS

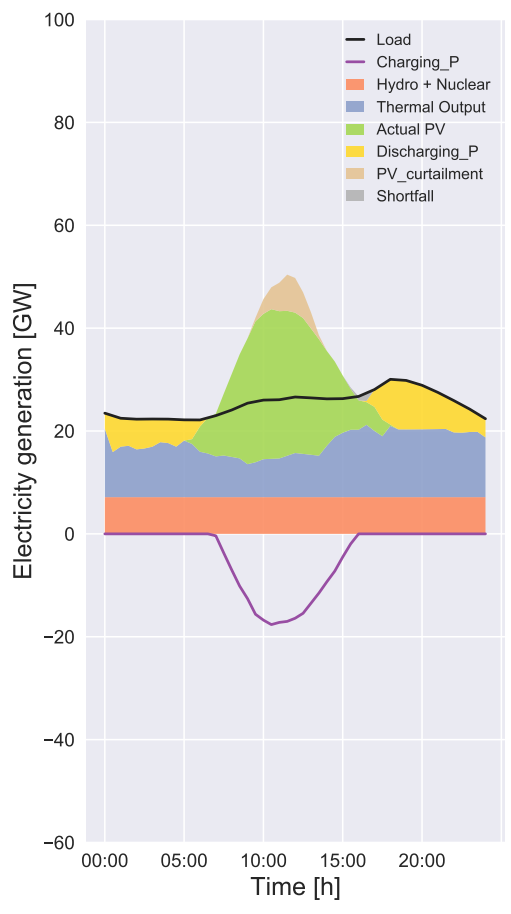

(b) 100 GWh BESS

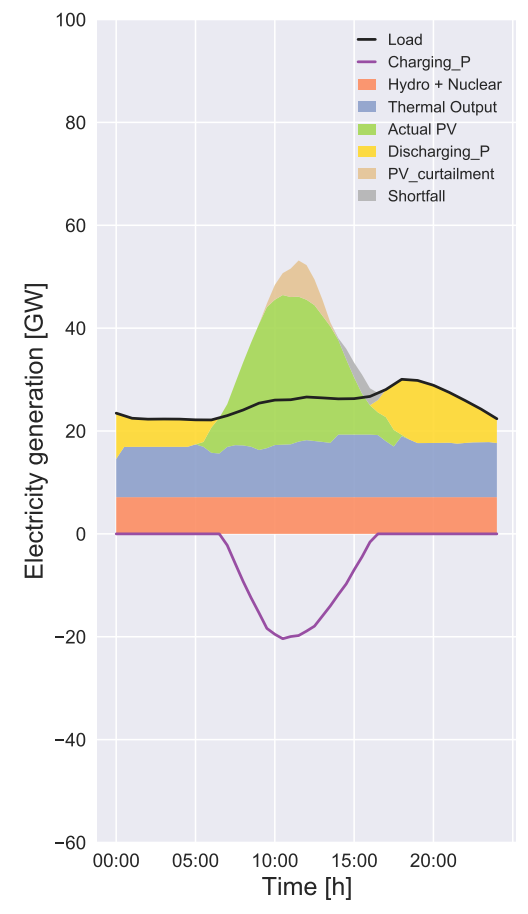

(c) 200 GWh BESS

Figure 15. Daily generation curve on April 10 (Case 1, PV: 50 GW).

In Figure 16, the larger the BESS capacity, the smaller the PV curtailment. Figure 16a is similar to Figure 15a because the number and outputs of the operating thermal generators are almost the same. The PV power output is curtailed after $13 \mathrm{~h}$ in Figure $16 \mathrm{~b}$ because the SoC of the BESS reaches $100 \%$ at that time. On the other hand, the PV curtailment cannot be seen in Figure 16c because the BESS capacity is large enough.

In Figure 17, the larger the BESS capacity, the smaller the PV curtailment. The curtailed PV energies in Figure 17 are larger than those in Figure 15.

In Figure 18, the larger the BESS capacity, the smaller the PV curtailment is. Relationship between Figure 18a and Figure 17a is similar to the relationship between Figures 16a and 15a. The SoC of the BESS reaches $100 \%$ at $11 \mathrm{~h}$ in Figure $18 \mathrm{~b}$ and at $13 \mathrm{~h}$ in Figure 18c, respectively. If the installed BESS capacity is larger than $200 \mathrm{GWh}$, the PV curtailment can be reduced more. However, the number and outputs of the operating 
thermal generators are almost minimum throughout the day in Figure 18c. Hence, the PV curtailment cannot be reduced to zero unless a large value of $x_{s o c}$ is allowed.

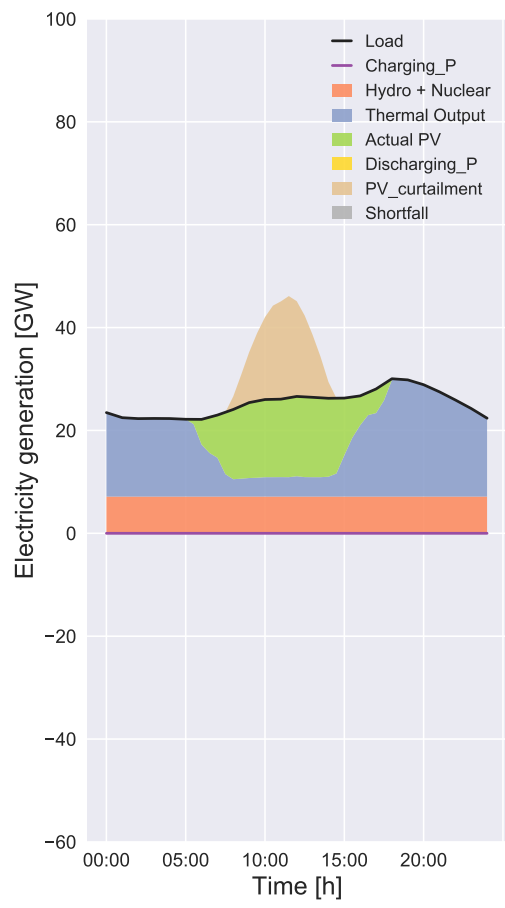

(a) 0 GWh BESS

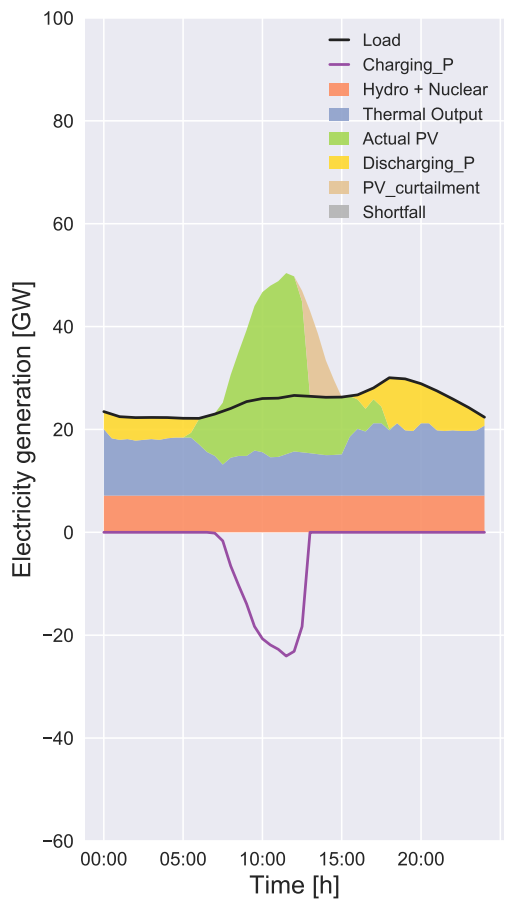

(b) 100 GWh BESS

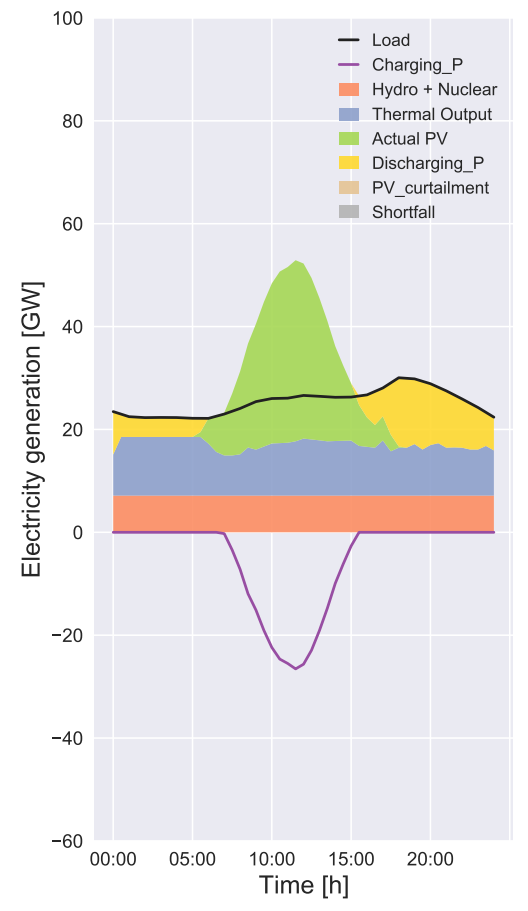

(c) 200 GWh BESS

Figure 16. Daily generation curve on April 10 (Case 2, PV: 50 GW).

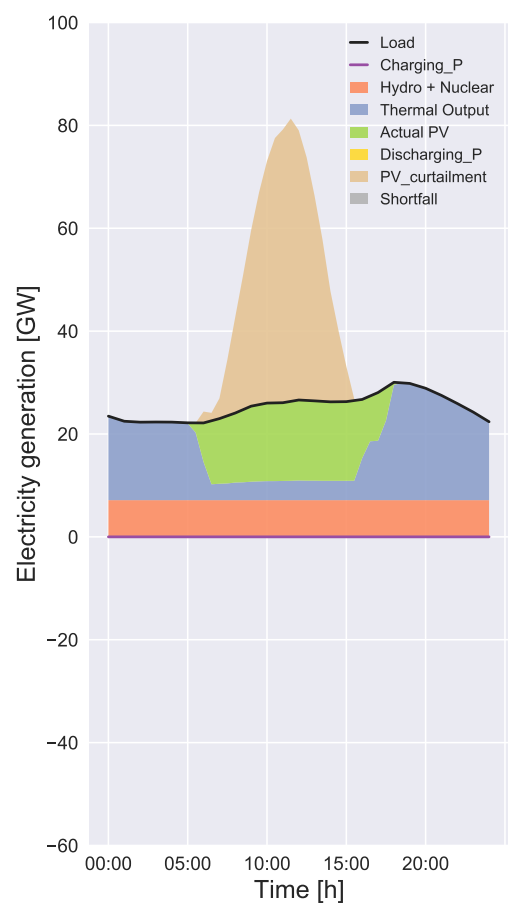

(a) 0 GWh BESS

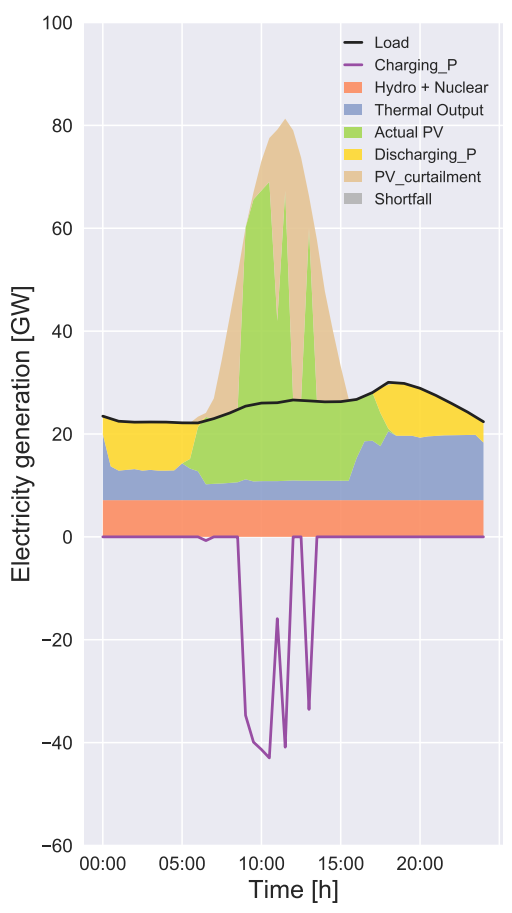

(b) 100 GWh BESS

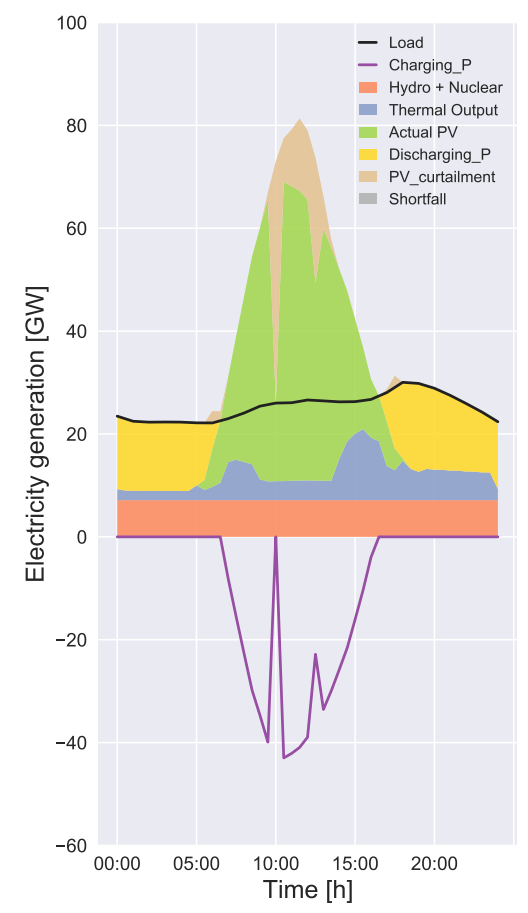

(c) 200 GWh BESS

Figure 17. Daily generation curve on April 10 (Case 1, PV: 100 GW). 


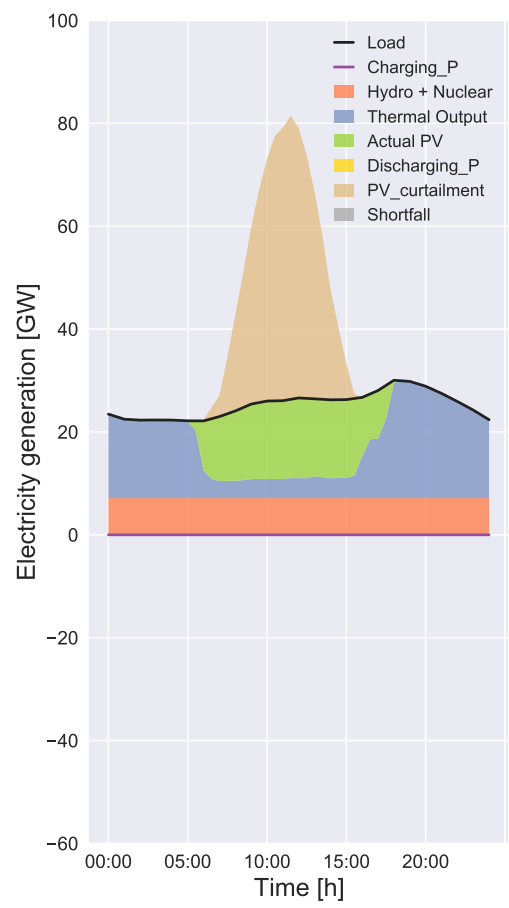

(a) 0 GWh BESS

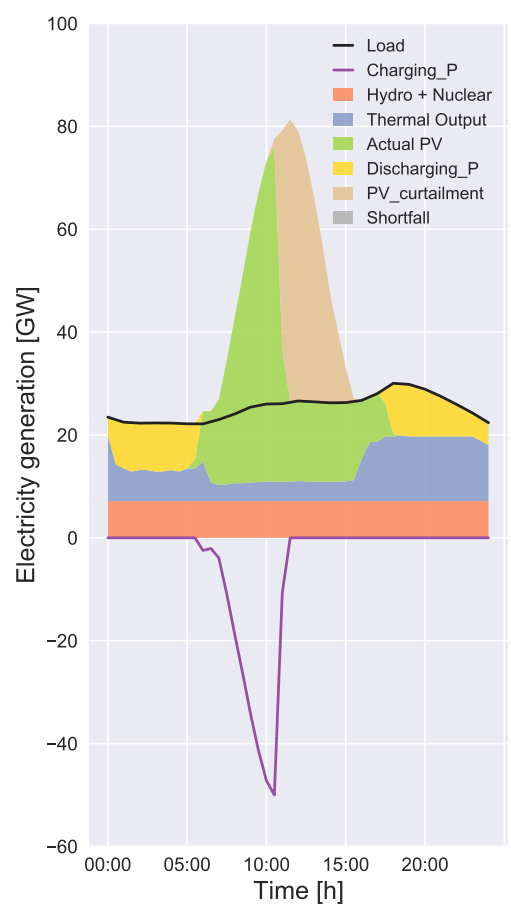

(b) 100 GWh BESS

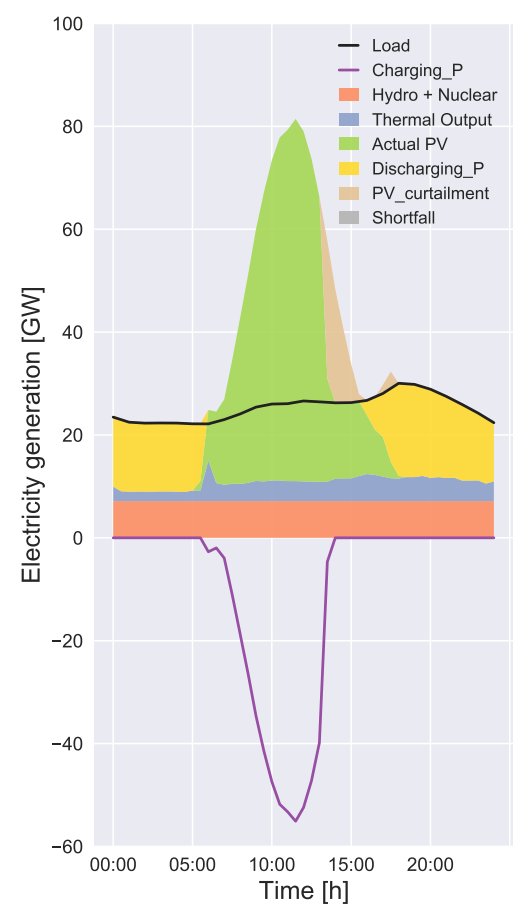

(c) 200 GWh BESS

Figure 18. Daily generation curve on April 10 (Case 2, PV: 100 GW).

\section{Conclusions}

In this paper, we proposed a method for rolling schedule update and operation of a number of generators and BESS in bulk power system based on the forecasted PV power output released every $3 \mathrm{~h}$ and the actual PV power output. The effectiveness of the proposed method was evaluated by numerical simulations conducted on the power system model of the Kanto area of Japan, where the grid capacity is approximately 60 GW, with 50 GW and 100 GW PV integration and with 100 GWh and 200 GWh BESS introduction. The proposed method was validated for April and January where the PV power output affects the supply-demand balance most and least, because the load demand is light and the solar irradiance is high in April whereas the former is heavy and the latter is low in January.

The results of the study indicate that the supply-demand imbalances such as energy shortfall or surplus are large even using BESS with conventional scheduling methods. The energy shortfall can be completely avoided and the energy surplus can be greatly reduced using BESS with the proposed method. The PV curtailment ratio with $100 \mathrm{GW} \mathrm{PV}$ integration was reduced from 55.1\% (without BESS) to 16.8\% (with 200 GWh BESS) in April whereas it was reduced from $34.0 \%$ (without BESS) to $2.6 \%$ (with 200 GWh BESS) in January. The impact of the proposed method with the BESS on the PV curtailment ratio becomes large with lower solar irradiance. The PV curtailment reduction ratios with $50 \mathrm{GW} \mathrm{PV}$ integration becomes $95.7 \%$ and 100\% with 200 GWh BESS in April and January, respectively, whereas those with 100 GW PV integration become 69.5\% and 95.2\% in April and January, respectively. The analysis of the installed PV capacity showed that the reduction effect of energy surplus was limited as the installed PV capacity became larger for the month with high solar irradiance. Further, the proposed method decreases the operational cost of generators while reducing energy imbalances.

Author Contributions: Conceptualization, R.U. and T.M.; methodology, R.U. and T.M.; software, R.U. and T.Y.; formal analysis, T.M., T.Y. and K.T.; investigation, R.U., T.M. and T.Y; resources, T.M.; data curation, H.O.; writing-original draft preparation, R.U. and T.M.; writing-review and editing, R.U. and T.M.; visualization, R.U., T.M. and T.Y.; supervision, R.U. and T.M.; project 
administration, T.M.; funding acquisition, T.M. All authors have read and agreed to the published version of the manuscript.

Funding: This work was partially funded by JST CREST Grant Number JPMJCR15K1 (5, Sanbancho, Chiyoda-ku, Tokyo, 102-0075, Japan) and Meijo Asian Research Center (1-501, Shiogamaguchi, Tempaku-ku, Nagoya, 468-8501, Japan).

Institutional Review Board Statement: Not applicable.

Informed Consent Statement: Not applicable.

Data Availability Statement: Third party data.

Conflicts of Interest: The authors have no conflict of interest to declare.

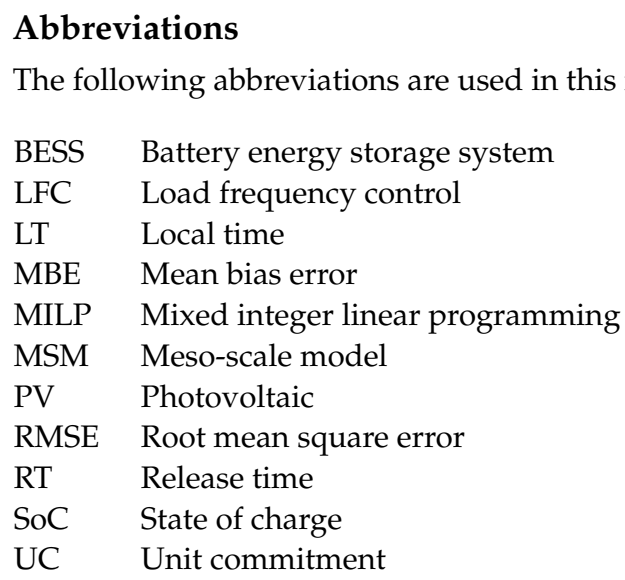

\section{Nomenclature}

Parameters

$\Delta T \quad$ Time interval of unit commitment calculation

$\eta \quad$ BESS charging efficiency

$\gamma \quad$ The schedule cycle

$\lambda_{i}^{k} \quad$ gradient of interval $k$ of piece-wise linear fuel cost function of unit $i$

$a_{i}, b_{i}, c_{i}$ parameters of fuel cost function for generator $i$

$C_{\text {init }}^{b} \quad$ Initial charge of the BESS

$\mathrm{C}_{\max }^{b} \quad$ Maximum charge of the BESS

$\mathrm{C}^{h} \quad$ Total LFC regulating capacity of hydro power plants [ MW ]

$C_{i}^{l f c} \quad$ LFC regulating capacity of generator $i$

$\mathrm{C}_{\mathrm{soc}} \quad$ Penalty cost for SoC difference

$\mathrm{DT}_{i} \quad$ Down time of generator $i$

$\mathrm{FC}_{i}(p) \quad$ Fuel cost function at power $p$ for generator $i[\mathrm{JPY} / \mathrm{h}$ ]

$\mathrm{LC}_{t} \quad$ Load curtailment cost of time $j[\mathrm{JPY} / \mathrm{h}$ ]

$\mathrm{N} \quad$ Number of thermal power plants [h]

$\mathrm{PC}_{t} \quad \mathrm{PV}$ curtailment cost of time $j[\mathrm{JPY} / \mathrm{h}$ ]

$\mathrm{p}_{d, t}^{a} \quad$ The estimated PV power output at time $t$ on day $d$

$\mathrm{p}_{d, t, R T}^{f} \quad$ The forecasted PV power output at time $t$ on day $d$ that was released at time $R T$

$P_{i n v}^{b c} \quad$ Rated charging power of the BESS

$P_{i n v}^{b d} \quad$ Rated discharging power of the BESS

$\mathrm{P}^{h} \quad$ Total output of Hydro Power

$\mathrm{P}_{t}^{l d} \quad$ Forecasted load demand at time $t$

$\mathrm{P}_{i}^{\max } \quad$ Maximum rated output of generator $i$

$\mathrm{P}_{i}^{\text {min }} \quad$ Minimum output of generator $i$

$\mathrm{P}^{n u} \quad$ Total output of Nuclear Power 


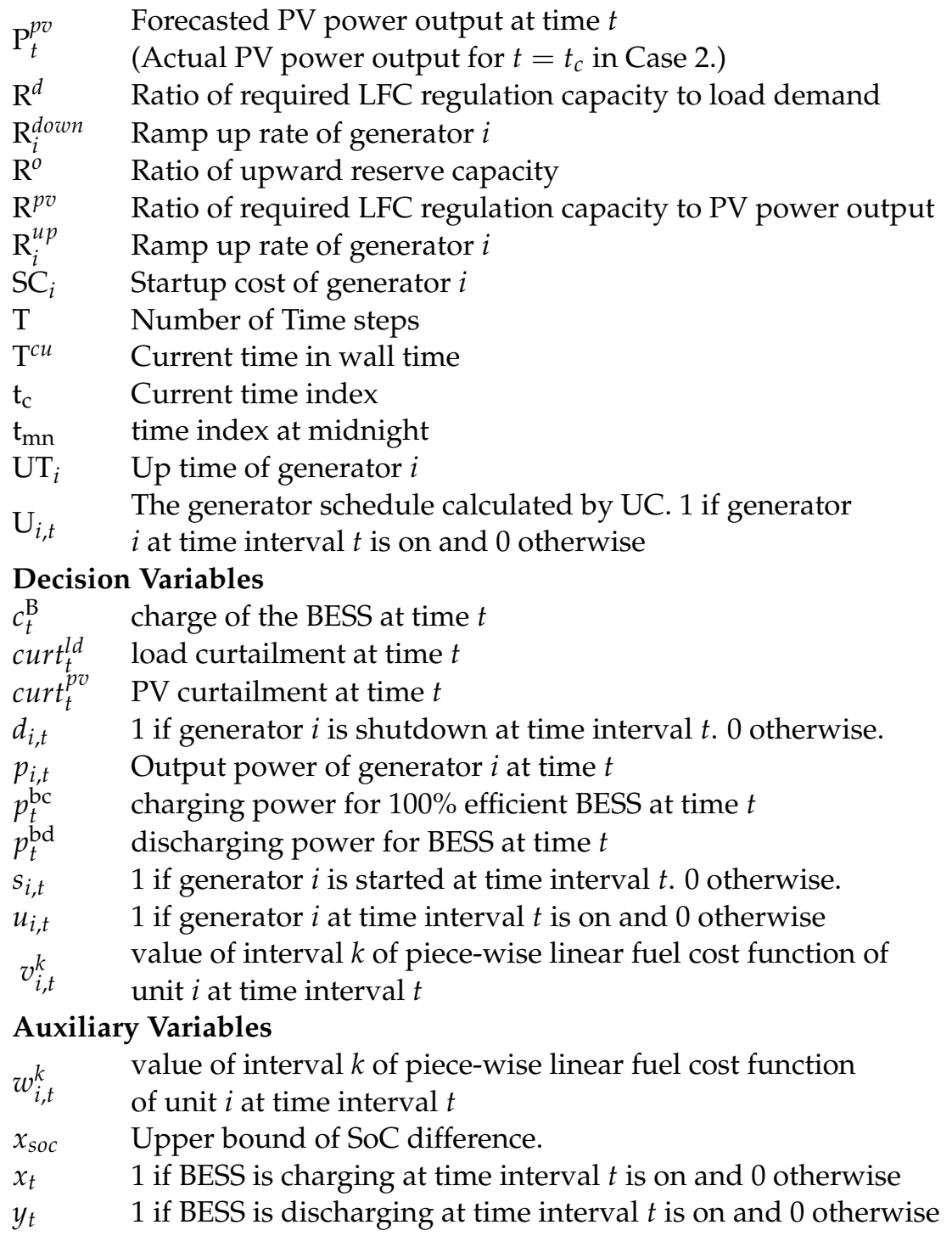

\section{References}

1. Present Status and Promotion Measures for the Introduction of Renewable Energy in Japan. Available online: http:/ /www.meti. go.jp/english/policy/energy_environment/renewable (accessed on 11 May 2020).

2. Domestic and Foreign Renewable Introduction and Agenda of The Calculation Committee for Procurement Price, etc. Available online: https:/ / www.meti.go.jp/shingikai/santeii/pdf/046_01_00.pdf (accessed on 11 May 2020). (In Japanese)

3. Long-Term Energy Supply and Demand Outlook (in Japanese). Available online: https://www.enecho.meti.go.jp/committee/ council/basic_policy_subcommittee/mitoshi/pdf/report_01.pdf (accessed on 11 May 2020). (In Japanese)

4. Japan Photovoltaic Energy Association (JPEA). Available online: http://www.jpea.gr.jp/en (accessed on 11 May 2020).

5. JPEA PV Outlook. Available online: http://www.jpea.gr.jp/pvoutlook2050.pdf (accessed on 11 May 2020). (In Japanese)

6. System Theory for Harmonized Power System Control Based on Photovoltaic Power Prediction. Available online: http: //www.cyb.sc.e.titech.ac.jp/harps/en/index.php/ (accessed on 11 May 2020). (In Japanese)

7. Masuta, T.; Oozeki, T.; Da Silva Fonseca, J.G., Jr.; Murata, A. Evaluation of Power Surpluses and Shortfalls Due to Error in Forecasting of Photovoltaic Generation Output. J. IEE Jpn. 2015, 192, 34-45. [CrossRef]

8. Masuta, T.; da Silva Fonseca, J.G.; Ohtake, H.; Murata, A. Study on Demand and Supply Operation Using Forecasting in Power Systems with Extremely Large Integrations of Photovoltaic Generation. In Proceedings of the 4th International Conference Sustainable Energy Technol, Hanoi, Vietnam, 14-16 November 2016.

9. Margeta, J.; Glasnovic, Z. Theoretical settings of photovoltaic-hydro energy system for sustainable energy production. Sol. Energy 2012, 86, 972-982. [CrossRef]

10. François, B.; Hingray, B.; Borga, M.; Zoccatelli, D.; Brown, C.; Creutin, J.D. Impact of Climate Change on Combined Solar and Run-of-River Power in Northern Italy. Energies 2018, 88, 290. [CrossRef]

11. Campana, P.E.; Li, H.; Yan, J. Dynamic modelling of a PV pumping system with special consideration on water demand. Appl. Energy 2013, 112, 635-645. [CrossRef] 
12. Shabani, M.; Mahmoudimehr, J. Techno-economic role of PV tracking technology in a hybrid PV-hydroelectric standalone power system. Appl. Energy 2018, 212, 84-108. [CrossRef]

13. Angarita, J.L.; Usaola, J.; Martínez-Crespo, J. Combined hydro-wind generation bids in a pool-based electricity market. Electr. Power Syst. Res. 2009, 79, 1038-1046. [CrossRef]

14. Ghadikolaei, H.M.; Ahmadi, A.; Aghaei, J.; Najafi, M. Risk constrained self-scheduling of hydro/wind units for short term electricity markets considering intermittency and uncertainty. Renew. Sust. Energ. Rev. 2012, 16, 4734-4743. [CrossRef]

15. Purvins, A.; Zubaryeva, A.; Llorente, M.; Tzimas, E.; Mercier, A. Challenges and options for a large wind power uptake by the European electricity system. Appl. Energy 2011, 88, 1461-1469. [CrossRef]

16. Yang, Z.; Li, K.; Niu, Q.; Xue, Y. A comprehensive study of economic unit commitment of power systems integrating various renewable generations and plug-in electric vehicles. Energy Convers. Manag. 2017, 132, 460-481. [CrossRef]

17. Luburić, Z.; Pandžić, H. FACTS devices and energy storage in unit commitment. Int. J. Electr. Power Energy Syst. 2019, 104, 311-325. [CrossRef]

18. Fu, B.; Ouyang, C.; Li, C.; Wang, J.; Gul, E. An Improved Mixed Integer Linear Programming Approach Based on Symmetry Diminishing for Unit Commitment of Hybrid Power System. Energies 2019, 12, 833. [CrossRef]

19. ElAzab, H.A.; Swief, R.A.; El-Amary, N.; Temraz, H. Unit Commitment Towards Decarbonized Network Facing Fixed and Stochastic Resources Applying Water Cycle Optimization. Energies 2018, 11, 1140. [CrossRef]

20. Zheng, Q.P.; Wang, J.; Liu, A.L. Stochastic Optimization for Unit Commitment-A Review. IEEE Trans. Power Syst. 2015, 30, 1913-1924. [CrossRef]

21. Abujarad, S.Y.; Mustafa, M.; Jamian, J. Recent approaches of unit commitment in the presence of intermittent renewable energy resources: A review. Renew. Sust. Energ. Rev. 2017, 70, 215-223. [CrossRef]

22. Luo, L.; Abdulkareem, S.S.; Rezvani, A.; Miveh, M.R.; Samad, S.; Aljojo, N.; Pazhoohesh, M. Optimal scheduling of a renewable based microgrid considering photovoltaic system and battery energy storage under uncertainty. J. Energy Storage 2020, $28,101306$. [CrossRef]

23. Wang, B.; Zhou, M.; Xin, B.; Zhao, X.; Watada, J. Analysis of operation cost and wind curtailment using multi-objective unit commitment with battery energy storage. Energy 2019, 178, 101-114. [CrossRef]

24. Kobayashi, D.; Masuta, T.; Ohtake, H. Coordinated operation of a battery energy storage system and thermal generators for supply-demand balance maintenance and efficient use of photovoltaic energy. Electr. Eng. Jpn. 2019, 207, $28-37$.

25. Palma-Behnke, R.; Benavides, C.; Lanas, F.; Severino, B.; Reyes, L.; Llanos, J.; Sáez, D. A Microgrid Energy Management System Based on the Roll-ing Horizon Strategy. IEEE Trans. Smart Grid 2013, 4, 996-1006. [CrossRef]

26. Warrington, J.; Hohl, C.; Goulart, P.J.; Morari, M. Rolling Unit Commitment and Dispatch With Multi-Stage Recourse Policies for Heterogeneous Devices. IEEE Trans. Power Syst. 2016, 31, 187-197. [CrossRef]

27. Vagropoulos, S.I.S.; Balaskas, G.A.; Bakirtzis, A.G. An Investigation of Plug-In Electric Vehicle Charging Impact on Power Systems Scheduling and Energy Costs. IEEE Trans. Power Syst. 2017, 32, 1902-1912. [CrossRef]

28. Saint-Pierre, A.; Mancarella, B. A Du-al-Horizon Scheduling Framework for DSO/TSO Interface Under Uncertainty. IEEE Trans. Smart Grid 2017, 8, 2186-2197. [CrossRef]

29. Kryzia, D.; Kopacz, M.; Kryzia, K. The Valuation of the Operational Flexibility of the Energy Investment Project Based on a Gas-Fired Power Plant. Energies 2020, 13, 1567. [CrossRef]

30. Gurobi Optimizer Reference Manual. Available online: http:/ /www.gurobi.com (accessed on 11 May 2020).

31. IEEJ Power and Energy, Japanese Power System Models. Available online: http://denki.iee.jp/pes/?page_id=141 (accessed on 26 June 2020).

32. IEEJ. Recommended practice for simulation models for automatic generation control. IEEJ Tech. Rep. 2016, 1386. Available online: https: / scholar.google.com/scholar?q=Investigating $\% 20$ R $\% 26$ D $\% 20$ Committee $\% 20 \% 282016 \% 29 \% 20$ Recommended $\%$ 20\{practice\%20for\%20simulation\%20models\%20for\%20automatic\%20generation\%20control.\%20In\%20IEEJ\%20Technical\%20 Report\% $\}\{201386\}$ (accessed on 1 December 2020). (In Japanese)

33. Agency for Natural Resources and Energy, Certificated and Actual Renewable Capacity by Prefecture. Available online: https:/ / www.fit-portal.go.jp/PublicInfoSummary (accessed on 9 September 2020). (In Japanese)

34. TEPCO: Electricity Forecast. Available online: https://www.tepco.co.jp/en/forecast/html/index-e.html (accessed on 26 June 2020).

35. Ohtake, H.; Uno, F.; Oozeki, T.; Yamada, Y.; Takenaka, H.; Nakajima, T. Estimation of satellite- derived regional photovoltaic power generation using a satellite- estimated solar radiation data. Energy Sci. Eng. 2018, 6, 570-583. [CrossRef]

36. Japan Meterological Agency: OUTLINE NWP March 2019. Available online: https://www.jma.go.jp/jma/jma-eng/jma-center/ nwp/outline2019-nwp/index.htm (accessed on 2 July 2020).

37. Ohtake, H.; Shimose, K.I.; da Silva Fonseca, J.G., Jr.; Takashima, T.; Oozeki, T.; Yamada, Y. Accuracy of the solar irradiance forecasts of the Japan Meteorological Agency mesoscale model for the Kanto region, Japan. Sol. Energy 2013, 98, 38-152. [CrossRef]

38. Ohtake, H.; Fonseca, J.G.d.S., Jr.; Takashima, T.; Oozeki, T.; Shimose, K.I.; Yamada, Y. Regional and seasonal characteristics of global horizontal irradiance forecasts obtained from the Japan Meteorological Agency mesoscale model. Sol. Energy 2015, 116, 83-99. [CrossRef] 
39. Bessho, K.; Date, K.; Hayashi, M.; Ikeda, A.; Imai, T.; Inoue, H.; Kumagai, Y.; Miyakawa, T.; Murata, H.; Ohno, T.; et al. An Introduction to Himawari-8/9- Japan's New-Generation Geostationary Meteorological Satellites. J. Meteor. Soc. Jpn. 2016, 94, 151-183. [CrossRef]

40. Meteorological Satellite Center (MSC) | Himawari Realtime Image. Available online: https://www.data.jma.go.jp/mscweb/ data/himawari/index.html (accessed on 26 June 2020).

41. Takenaka, H.; Nakajima, T.Y.; Higurashi, A.; Higuchi, A.; Takamura, T.; Pinker, R.T.; Nakajima, T. Estimation of solar radiation using a neural network based on radiative transfer. J. Geophys. Res. 2011, 116, D08215. [CrossRef]

42. Solar Radiation Consortium (Non Profit Organization). Available online: http://www.amaterass.org/contact.html (accessed on 2 July 2020). 